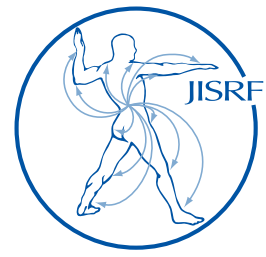

\title{
Metallic Modular Taper Junctions in Total Hip Arthroplasty
}

\author{
McTighe $T^{1}$, Brazil $D^{2}$, Clarke I ${ }^{3}$, Keppler $L^{4}$, Keggi $J^{5}$, Tkach $T^{6}$, McPherson $E^{7}$
}

\begin{abstract}
The emergence of modularity in total hip arthroplasty (THA) in the 1980s and 1990s was based on the fact that the benefit of these design features outweighed the risk. The use of metallic modular junctions presents a unique set of advantages and problems for use in THA. The advantages include improvement in fit and fill of the implant to bone, restoration of joint mechanics, reduced complications in revision surgery and reduction of costly inventory. However, the risks or concerns are a little harder to identify and deal with. Certainly corrosion, and fatigue failure are the two most prevalent concerns but now the specifics of fretting wear and corrosive wear increasing particulate debris and the potential biological response is having an impact on the design and potential longevity of the reconstructed hip. Material and designs are facing a shorter life expectancy than what was previously thought, mostly due to an increasing level of physical activity by the patient. Because there are no accurate laboratory test whereby the service life and performance of these implants can be predicted, early controlled clinical evaluations are necessary. Early publication of testing and clinical impressions should be encouraged in an attempt to reduce exposure to potential at risk patients, implants and material. The reduction and possible elimination of risks will require a balancing of all the variables requiring a multidisciplinary endeavor.

This paper is designed to review the risk factors, and benefits of modular junctions in total hip arthroplasty (THA). Also some basic engineering principals that can reduce risk factors and improve functionality of modular junctions.
\end{abstract}

Keywords: hip, arthroplasty, debris, fretting, modularity, taper, metal ions, and metallurgy

Level of Evidence: AAOS Therapeutic Level III

\section{Introduction}

In dealing with the vast and complex problems associated with reconstructive total hip arthroplasty (THA), one of our tools is the use of metallic modular junctions. [1,2,3,4] Recently there has been considerable discussion and debate surrounding the risk benefit ratio is using modularity. [5,6,7] Modularity selected for THA is typically determined by ascertaining the intended function of the modular junction in the overall reconstruction of the hip. The most

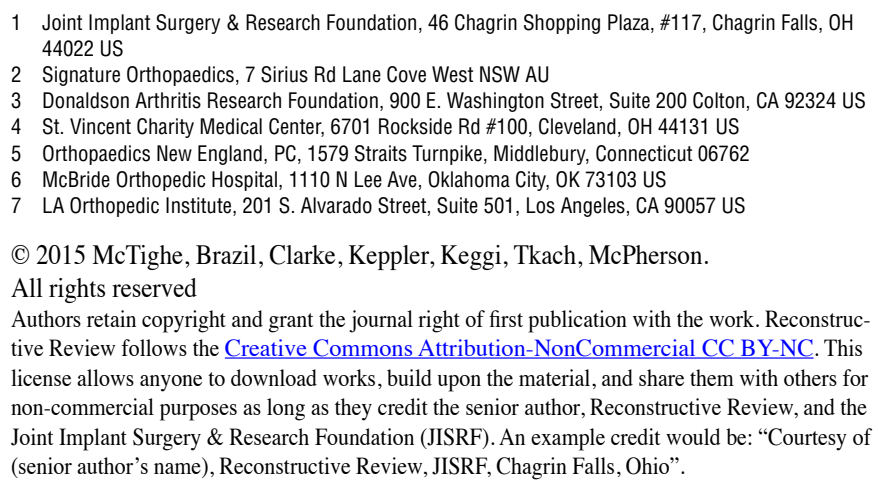

(c) 2015 McTighe, Brazil, Clarke, Keppler, Keggi, Tkach, McPherson. All rights reserved

Authors retain copyright and grant the journal right of first publication with the work. Reconstructive Review follows the Creative Commons Attribution-NonCommercial CC BY-NC. This license allows anyone to download works, build upon the material, and share them with others for non-commercial purposes as long as they credit the senior author, Reconstructive Review, and the Joint Implant Surgery \& Research Foundation (JISRF). An example credit would be: "Courtesy of (senior author's name), Reconstructive Review, JISRF, Chagrin Falls, Ohio". 
suitable modular designs are those that are well tolerated by the body and can withstand increased cyclic loading in an ever-demanding environment, especially with the physical activities and expectations of today's patients. Often, the totality of factors that must be assessed when choosing a modular junction for implantation is not completely considered. Typically, the surgeon considers only one issue, which is material strength. Other critical factors of modularity selection include corrosion resistance, cost, and ability to manufacture. $[3,6,8]$

Individual modular design parameters can offer significant advantages for both fit and fill of implant to bony structures while providing more options for intraoperative customization of joint mechanics and significant economic value in reducing levels of finished goods inventory (Figure 1). [6,9] Now, amid reports of clinical incidents in which metal modular junctions have demonstrated fretting, corrosion, and pseudotumors, there is renewed interest as to what causes these junctions to fail. $[9,10,11,12,13]$ The recent fall in the use of modularity can be contributed primarily to concerns with inflammatory reactions to metal debris. Can failures be predicted or avoided? When a failure does occur what can be done about it?

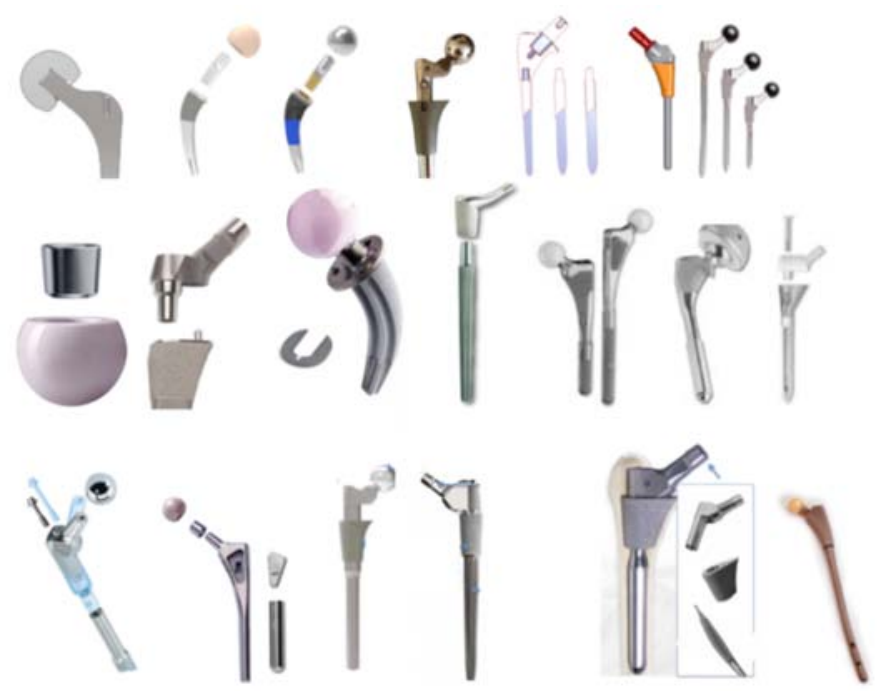

Figure 1. Example of various modular junctions.(Courtesy of JISRF)

\section{Current Concerns with Metallic Materials}

Implant compatibility and particulate debris in THA is not a new concern and has been an issue of debate since the first attempt to replace a hip joint in the 1890s. One of our greatest allies in reconstruction is the use of metals for implant fabrication; however, this requires an understanding of the biological and engineering principles involved. $[8,14]$
While modular designs represent an advance in the ability to precisely fit the implant to the bone and restore joint mechanics, the mechanical integrity of the assembled component must be fully tested before clinical use. Fabrication methods, tolerances, surface characteristics, materials, electrochemical environment and mechanical environment are all critical factors that need careful consideration in evaluating the long-term performance of modular interfaces. In evaluating the mechanical performance of modular femoral stems, there is no single test that can adequately represent the various conditions that a hip stem maybe subjected to in vivo.

Biocompatibility is mainly determined by the implant surface properties. When a metal implant comes in contact with biological tissue, the following occurs:

1. The implant is first covered with proteins from the body fluids, then cells may attach according to the implant surface properties.

2. The body will either tolerate a biocompatible implant or a foreign body reaction will occur. For metals, this depends on the surface properties of the implant, such as surface chemistry and roughness. Proteins and cells interact differently on surfaces with different properties (Figure 2). If the implant is biocompatible, the inflammation will decrease. If the implant is not biocompatible, a chronic inflammation can occur with possible consequence of a foreign body reaction. In addition, damaged surfaces may evolve to release ions that are potentially allergen-

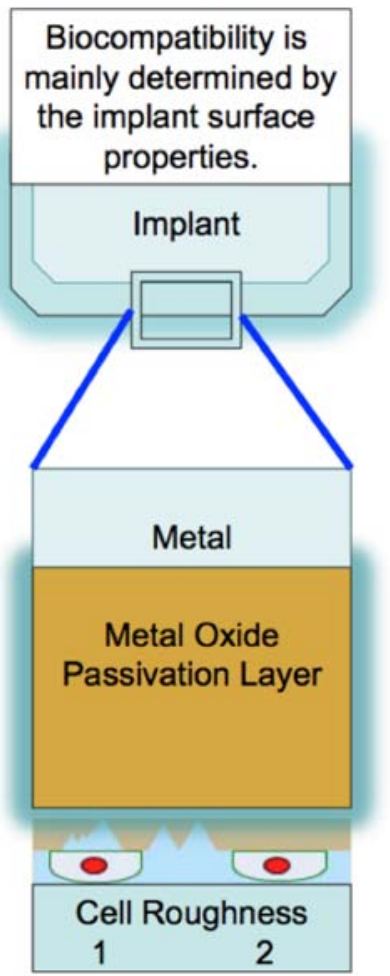

Figure 2. Chart showing the Biocompatibility of Metallic Implants. Cell one is strongly attached because the surface is rougher than cell two attached to a smooth surface. ic/toxic. This is the beginning of the corrosion process (Figure 3,4,5).

It seems that every 10 years, concern regarding problems from implanted materials resurface. It has been almost four decades since Willert first described the problem of polyethylene wear leading to peri-prosthetic inflammation, granuloma, bone resorption, and implant loosening. [15] Bobyn et al presented an AAOS scientific exhibit in 1993 reviewing problems and solutions with particulate debris in THA. [10] This review covered concerns with 


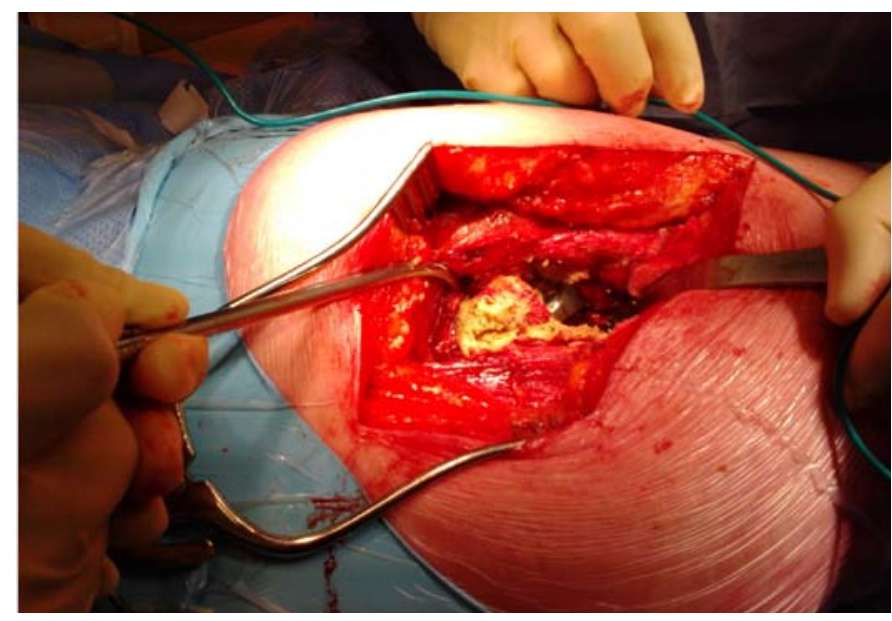

Figure 3. Extensive necrosis as a result of Adverse Reaction to Metal Debris. (Courtesy of E. Smith)
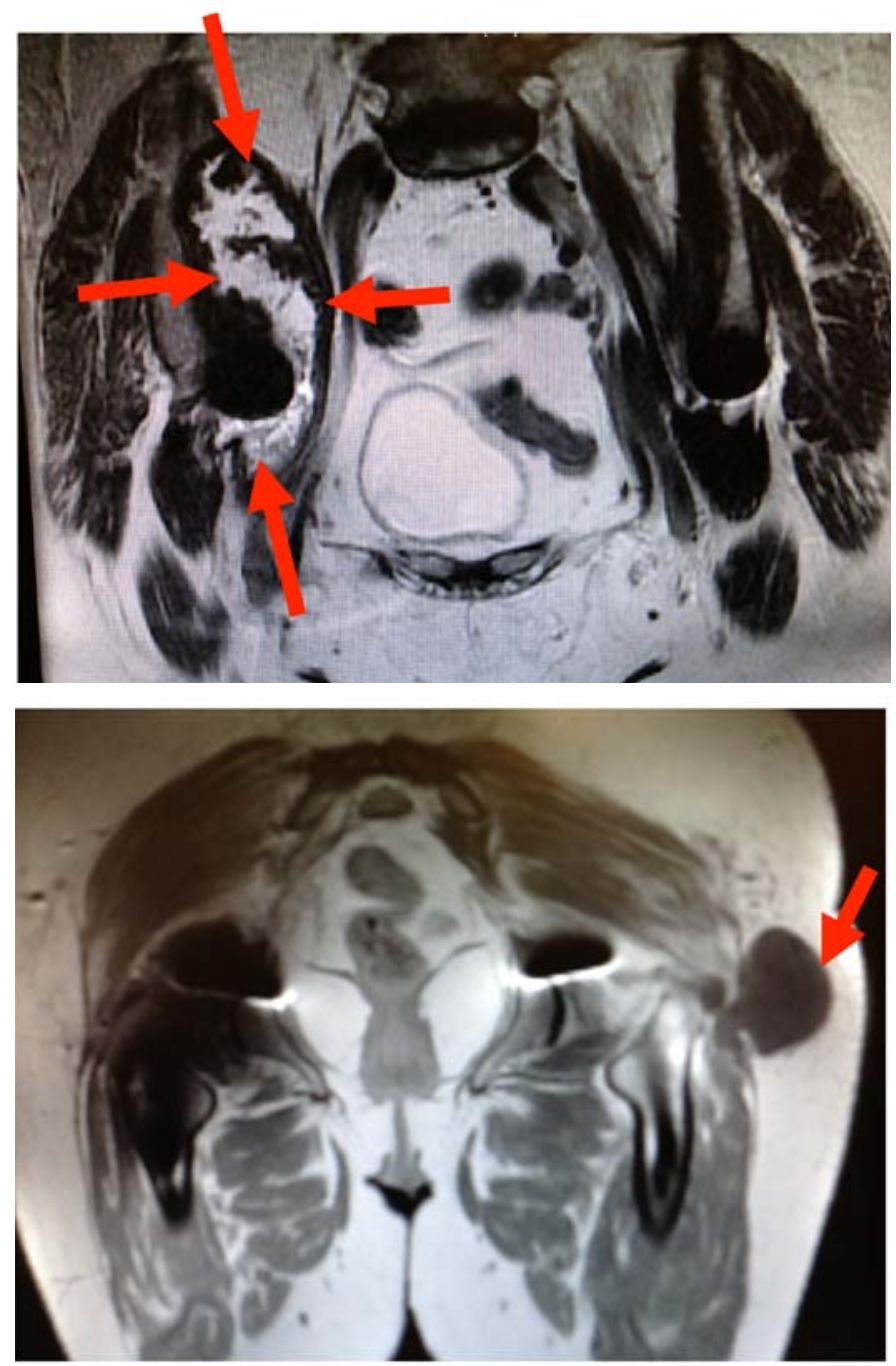

Figure 4. Examples of magnetic resonance images of a pseudotumor (arrow) adjacent to a metal-on-metal hip prosthesis / Adverse Reaction to Metal Debris (ARMD) (Courtesy of E. Smith)

modularity (tapers, dovetails, pads, and stem segments) in both the femoral and acetabular component. So what is different today? Why the increased concern?

Material selection and fabrication has not been altered
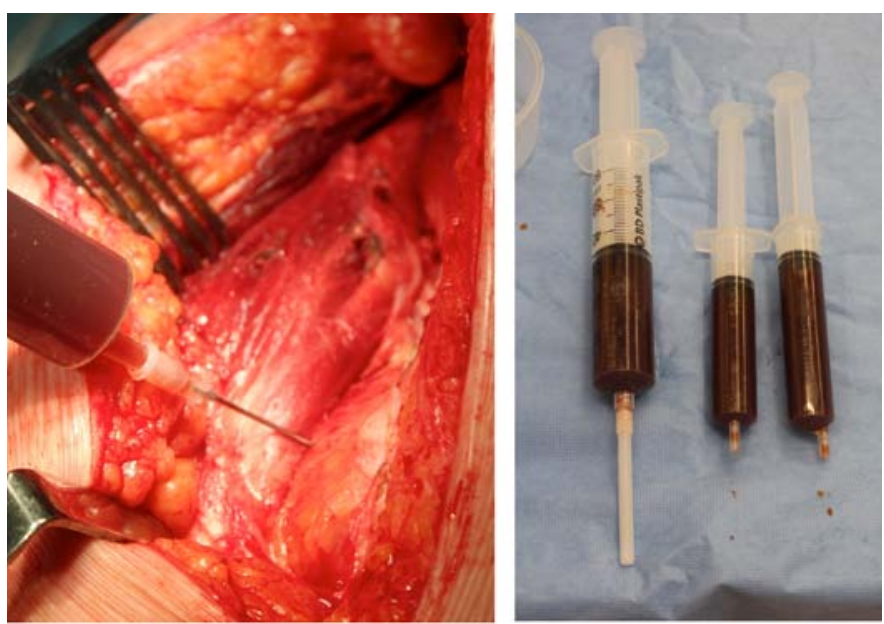

Figure 5. Capsular tension and wear slurry aspiration in a patient with ARMD. (Courtesy of E.Smith)

to any great degree since the 1990s. However, three significant factors have come into play. First, volume of total joint surgery has increased (U.S.), and primary THA is projected to increase by $174 \%$ to 572,000 per year by 2030. [16] Second, THA is being done on younger patients and patient activity overall within all age groups has increased. Third, small design alterations may have significant negative outcomes. $[7,8,9,10,13]$

Another possible factor is the reluctance of surgeons to provide postoperative precautions with regard to early physical activities. Regardless of material or design, the surgical process for preparing and inserting a total hip stem requires a fracture healing response of the bone. Bone remodeling initially occurs under the stable condition of fracture with rigid fixation and no gap formation-the key being stability of implant to bone to maintain the biological healing response. [17] Modular junctions are designed to work in a stable environment. If the implant has instability and micro-motion, it is very likely the modular junction will encounter increased stress that can lead to a breakdown of the stability of the modular junction, which results in fretting and or corrosion.

Recent concerns with modular tapers can be attributed to the results with metal-on-metal (M-o-M) hip resurfacing (HR) and by extension, the use of large heads (greater than $36 \mathrm{~mm}$ ) in THA. [18] Small diameter heads (28-32 $\mathrm{mm}$ ) have had favorable results since the late 1980s. [19,20,21] However, the market demand to reduce dislocations in THA pushed the M-o-M bearings into larger head diameters. While it took time to see the problems with large M-o$\mathrm{M}$ heads, it is also possible that the signs were overlooked. Since 1956, there have been reports of soft tissue tumors caused by metallic alloys. [22] By 1998, Jacobs reported that the taper junction between head and stem was responsible for the significant increase in titanium and cobalt concentrations in the patient, even when the prostheses were 


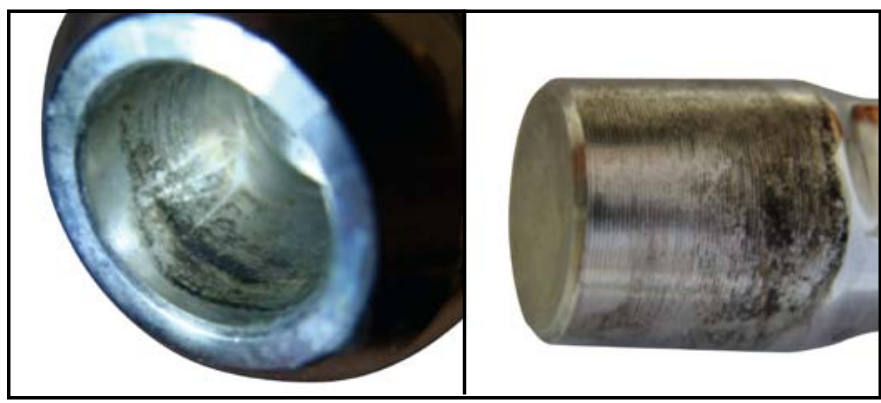

Figure 6. Fretting abrasion wear and corrosion on a head (Co-Cr-Mo) head \& stem trunnion taper (Ti-alloy).

functioning well [23] (Figure 6). In the 2010 National Joint Registries of England and Wales (NJR), problems were becoming obvious with the focus being directed to the taper junction. [24] In 2012, the Medicines and Healthcare products Regulatory Agency (MHRA) in the United King-
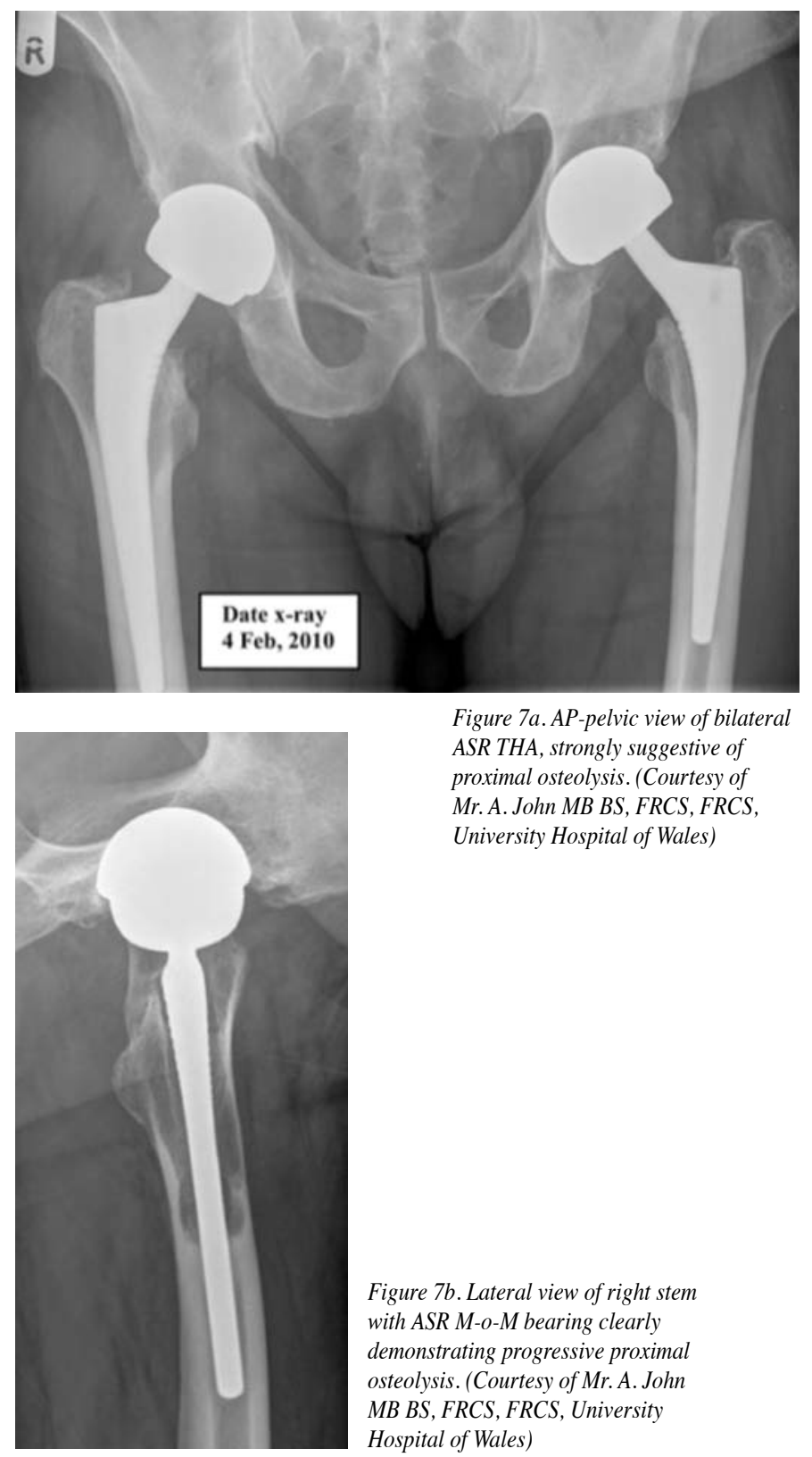

Figure $7 b$. Lateral view of right stem with ASR M-o-M bearing clearly demonstrating progressive proximal osteolysis. (Courtesy of Mr. A. John $M B$ BS, FRCS, FRCS, University Hospital of Wales)

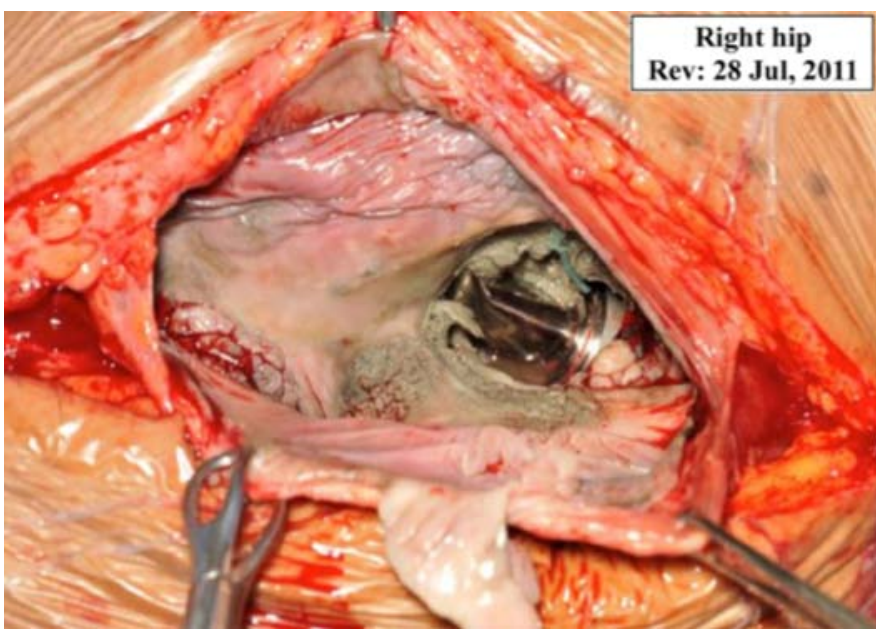

Figure $7 c$. Initial view of femoral neck and head at revision surgery following removal of extensive pool of green-yellow fluid. (Courtesy of Mr. A. John MB BS, FRCS, FRCS, University Hospital of Wales)

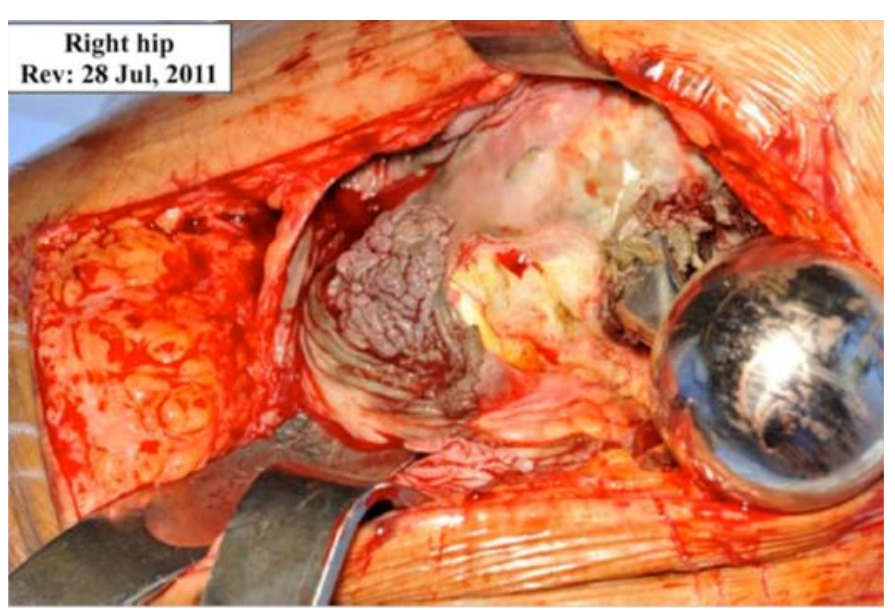

Figure $7 d$. Extraction of head revealing mass of necrotic tissue around proximal femur. (Courtesy of Mr. A. John MB BS, FRCS, FRCS, University Hospital of Wales)

dom (UK) issued new guidelines on larger head $(+36 \mathrm{~mm})$ forms of "M-o-M" hip implants. Patients with a large Mo-M hip implant should have annual health checks for life as compared to previous recommendation of up to five years. (Figure 7a, 7b, 7c, 7d).

In May 2015, Michael Morlock published a review paper on tapers showing examples of head/neck taper fractures with a Ti-alloy stem taper and a titanium sleeve connector to the femoral head [25] (Figure 8). He further

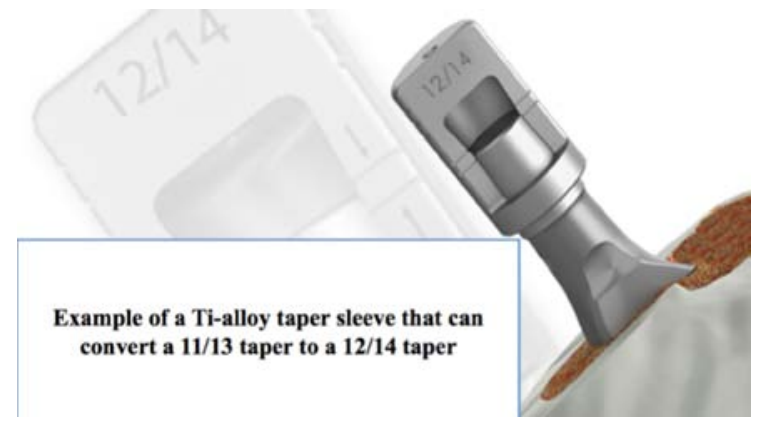

Figure 8. Illustration Showing a Ti-alloy taper sleeve 
pointed out in his paper that the European Union with the establishment of a Scientific Committee on Emerging and Newly Identified Health Risks (SCENIHR) working group investigating "The safety of M-o-M joint replacements with a particular focus on hip implants about the M-o-M problems."

The preliminary consensus of this working group was published in September 2014 and addressed this topic explicitly: "This metal debris can originate either from the bearing articulation directly or from the modular taper junction between prosthesis head and stem. In the past, the taper has only been reported anecdotally as the origin of problems. Recently, the taper has emerged as the focus of attention, since large modular metal heads for M-o-M arthroplasty were introduced due to their ability to reduce dislocation risk, which is the second major complication in hip arthroplasty. These larger heads, however, put larger loads on the taper junction and are suspected to be responsible for the problems suddenly occurring at this side." $[21,26]$

The success of a self-locking taper is influenced by

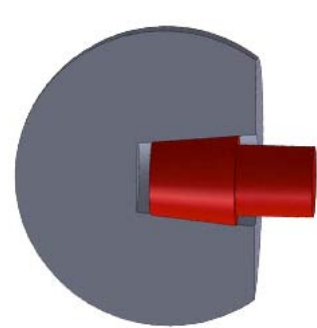

Figure 9a. Schematic of headl neck taper.

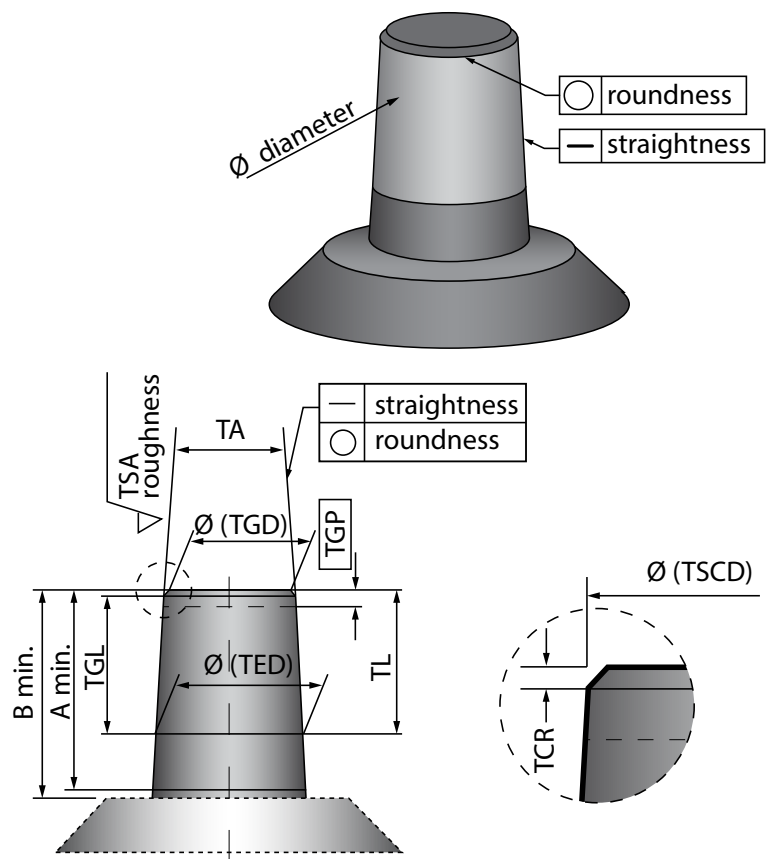

Figure 9b. Characteristics of a head/neck taper. (Redrawn from CeramTec Source by Chris Burges) [28] ative dimensions of the two components (male and female regions), and a design decision to have interference along a specific part of the taper's circumference and length. The area of interference contact must be adequate to maintain integrity under functional (loaded) conditions, while the surface finish of the components must be specific to the physical and mechanical properties of each component's material. [17,34]

In the last two decades, manufactures have been altering femoral stem trunnions from various tapers such as $14 / 16$ to $12 / 14$ to $11 / 13$ (Figure 10). The Ceramtec 12/14

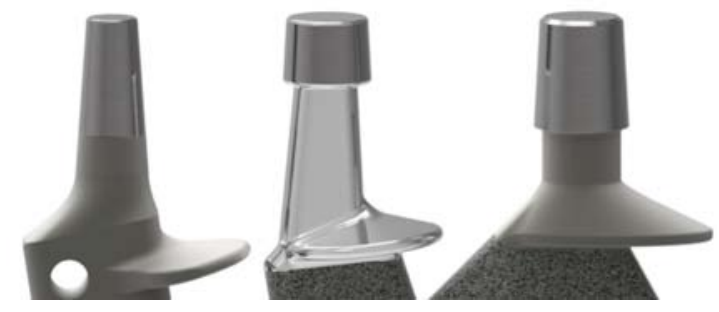

Figure 10. Illustration Showing Different Taper Designs by Manufactures. (Courtesy of Chris Burgess, Signature Orthopaedics Ltd.)

taper at one time has been referred to by most in Europe as a European 12/14 taper. This term was not trademarked, and some companies began altering the manufacturing tolerance as originally produced from Ceramtec. The term "Euro taper" still is used by most in Europe to describe an off-the-shelf 12/14 Ceramtec taper. [27,28]

A range of different Morse taper angles, component tolerances and sizes, and surface finishes exist within commercially available hip systems. While manufacturers do not recommend mixing and matching of component brands, a number of surgeons have been mixing and matching without complications, provided the products used have the same manufacturing tolerances. [29] A survey published in 2005 from the New Zealand Orthopaedic Association showed that $23 \%$ of the surgeons had implanted mismatched components within the last five years [36] (Figure 11).

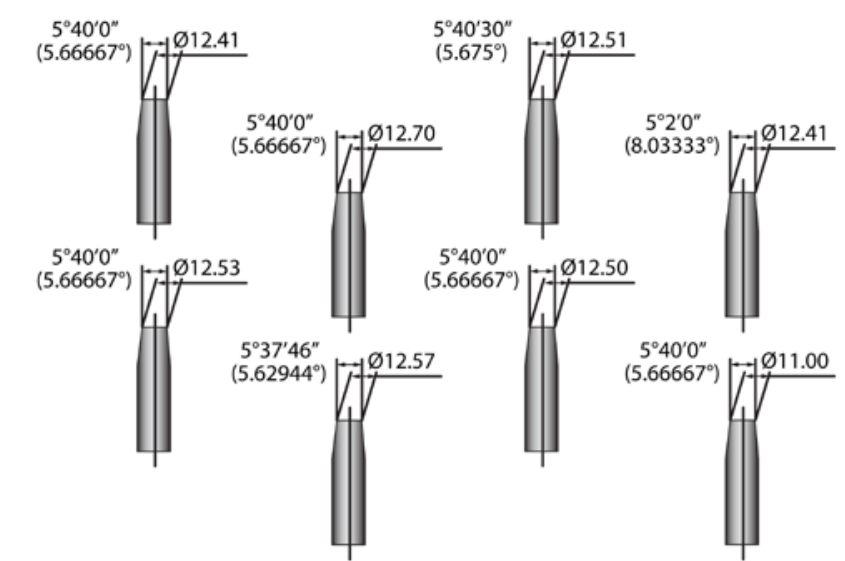

Figure 11. Various designated "12/14" Tapers (Redrawn from CeramTec Source by Chris Burges) [28] 
Amid rising concerns of modular junctions, it is important to remember most hip implant revisions are not the cause of modularity. Aseptic loosening, osteolysis/wear, instability/dislocation, infection and periprosthetic fracture remain as the major reasons for hip revision surgery. One

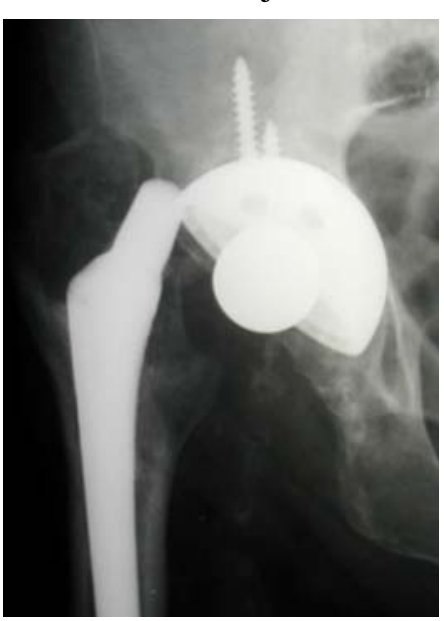

Figure 12a. Detachment of modular head can damage stem trunnion. (Courtesy of J. Keggi)
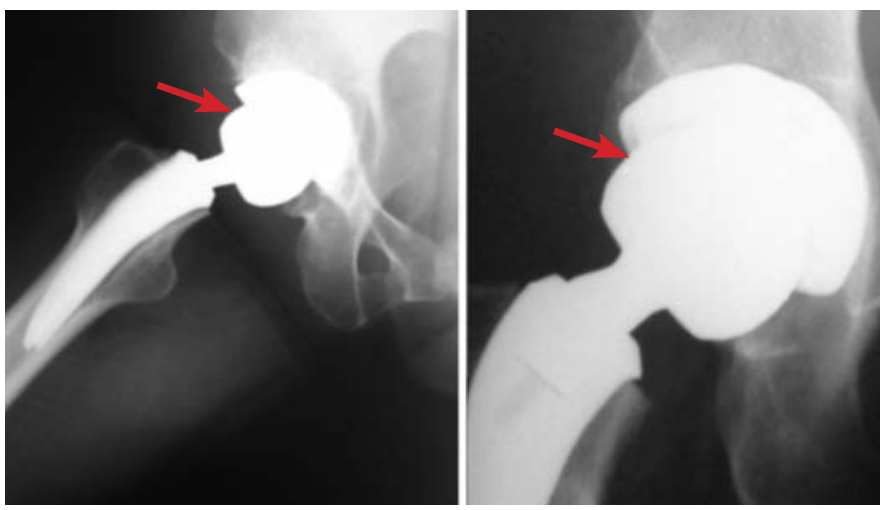

Figure 12b. Post-op X-Rays demonstrating mismatch between modular head and modular cup liner. (36mm head-32mm liner). The advantage here is this stem has a modular neck so a simple exchange replacing neck (new trunnion) and head to match poly liner. (Courtesy of JISRF)

risk of dissociation of the head in association with dislocation and attempts at closed reduction. [43] This can often leave a well-fixed stem in place with some degree of damage to the stem trunnion. This may be an indication to use a modular trunnion sleeve to engage with the modular head, especially if you intend to use a ceramic head (Figure 13). Multimodularity in stem designs, along with the use of larger head diameters, brings with it serious concerns with regard to corrosion and its biological reaction to increased metal ions and particulate debris.

Figure 13. Modular ceramic head with a Ti-alloy sleeve inserted into the femoral head is helpful when stem trunnion is damaged.

\section{Corrosion}

Corrosion of metals has many different mechanisms that all have independent driving forces. Corrosion can be defined as the degradation of a material due to a reaction with its environment. There are many forms of corrosion and no universally accepted terminology is in use. The following terminology is based on current use by NASAKennedy Space Center. [32]

\section{Galvanic corrosion}

Galvanic corrosion is an electrochemical action of two dissimilar metals in the presence of an electrolyte and an electron conductive path. It occurs when dissimilar metals are in contact.

Worldwide ISO standards recognize the detrimental effect of galvanic corrosion cells that can be established in the body, and this should be considered during implant design. [8] When reduced taper length is combined with larger femoral heads, the outcome has been that industry experiences a new failure mode in THA "trunnionosis." [33] One factor that can drive the trunnionosis phenomena is the use of different materials at modular junctions. Fundamental science states that two different materials in a conducting media will generate a battery or corrosion cell. Consequently, all differing materials mated together in the human body will set up a corrosion cell to some extent. The extent on the corrosion cell is affected by the fluid conductivity and galvanic potential difference between the two materials. [8]

\section{Pitting corrosion}

Pitting corrosion is localized corrosion that occurs at microscopic defects on a metal surface. The pits are often found underneath surface deposits caused by corrosion product accumulation.

\section{Crevice corrosion}

Crevice or contact corrosion is the corrosion produced at the region of contact of metals with metals or metals with nonmetals.

\section{Stress corrosion}

Stress corrosion cracking is caused by the simultaneous effects of tensile stress and a specific corrosive environment. Stresses may be due to applied loads, residual stresses from the manufacturing process, or a combination of both. (Courtesy of JISRF)

\section{Corrosion fatigue}

Corrosion fatigue is a special case of stress corrosion 


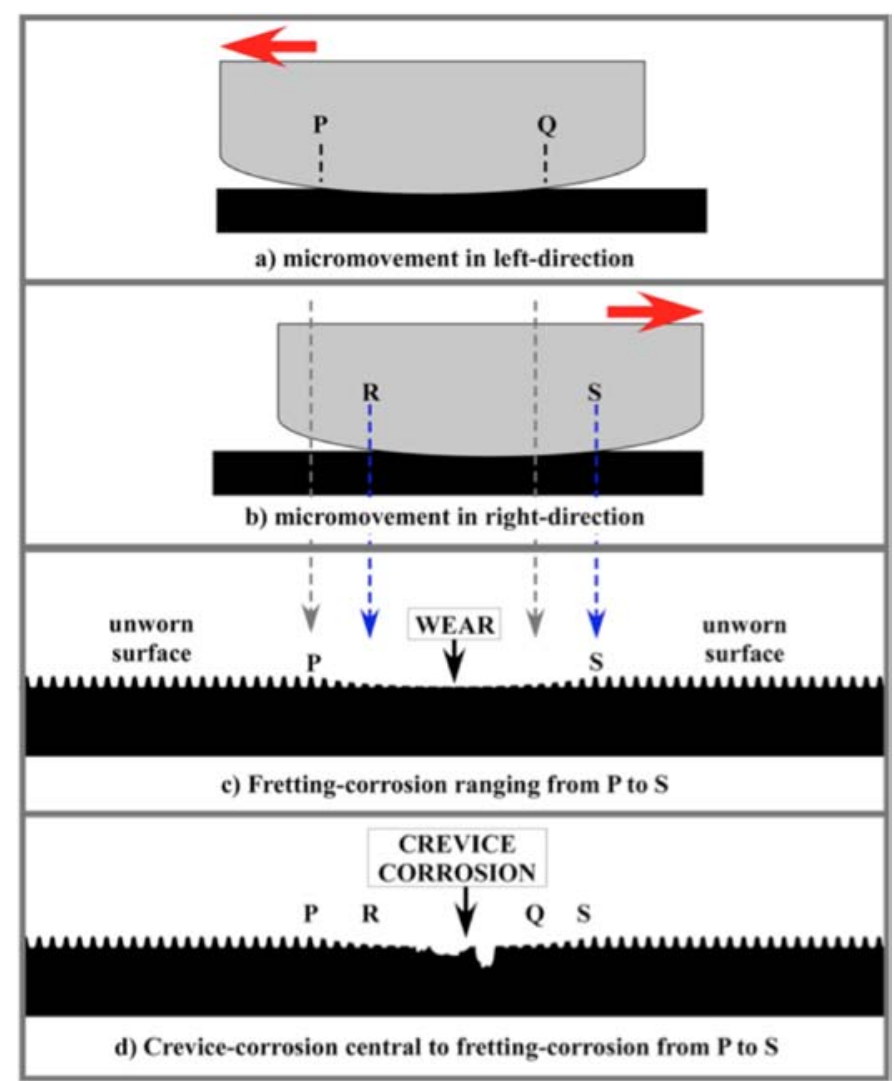

Figure 14a. Schematic illustrating that oscillatory motions as small as 10-100um can induce wear and mechanically-assisted crevice corrosion (MACC). Such relative motion is unavoidable because modular junctions inherently introduce parts of different rigidity (size, shape) and different alloys (stiffness criteria). (Courtesy of Ian Clarke)

caused by the combined effects of cyclic stress and corrosion. No metal is immune from some reduction of its resistance to cyclic stressing if the metal is in a corrosive environment.

\section{Fretting corrosion}

Fretting corrosion is the rapid corrosion that occurs at the interface between contacting, highly loaded metal surfaces when subjected to slight vibratory motions (Figure $14 a, 14 b)$.

Using these definitions, one can better understand the mechanisms behind product deterioration among the different THA junctions.

\section{Challenges with the Neck/Stem Modular Junction}

Fretting corrosion has recently been attributed to the decline in the clinical acceptance of modular neck hip implants. It has also been the reason for the recall of two products (Rejuvanate ${ }^{\mathrm{TM}}$ and $\mathrm{ABGII}{ }^{\mathrm{TM}}$ ) by Stryker Or-
(I)

a) Repeated disruption metal's (M) surface oxide (O) (passive layer)

b) Repeated formation metal's (M) surface oxide $(\mathrm{O})$

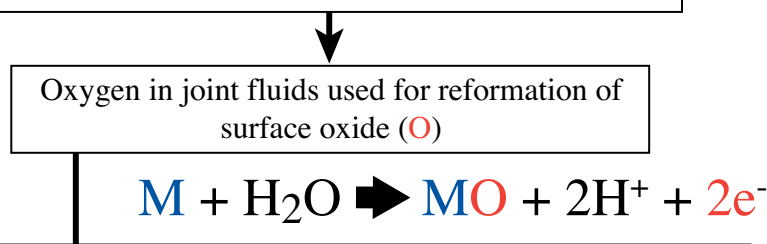

Chloride ions (CI) available to combine with hydrogen ions $\left(\mathrm{H}^{+}\right)$ to form acid (HCL)

(V)

$$
\mathrm{H}^{+}+\mathrm{CI}^{-} \rightarrow \mathrm{HCI}
$$

Fluid in taper becomes more acidic, oxygen concentration drops, fretting continues and crevice corrosion is initiated

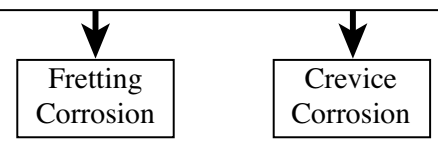

Figure 14b. Electrochemical reactions involved in mechanically-assisted crevice corrosion (MACC: redrawn from data in Gilbert et al, 1997). Cyclic loading is a necessary hip function and the resulting micromotion can disrupt the protective oxide film on metal surfaces. Ideally this will quickly reform, the metal combining with oxygen from the local environment and in the process releasing hydrogen and negativelycharged electrons. Under adverse conditions, the fretting continues, the oxygen concentration is depleted, and the formation of a protective oxide layer is compromised. In addition the surrounding environment is becoming more acidic as the hydrogen ions recombine with chlorine ions to form hydrochloric acid, thereby promotion dissolution of the metal surface. (Gilbert et al 1997) (Courtesy of Ian Clarke)

thopaedics, Mahwah, NJ. [7,8,34,35,36] A main driving mechanism behind fretting corrosion is stress, or load. Increasing the stress at the modular junction will proportionally increase the extent of the fretting corrosion (Figure 15). Reviewing the design of the modular junction of these products indicates that the application of some fundamental engineering principles could have reduced the probability of fretting corrosion. Figure 16a and $16 \mathrm{~b}$ shows the length of taper support versus the offset of the modular neck for the Stryker, Wright Medical, and TSI/ ARC ${ }^{\text {TM }}$ systems. The recalled products from Stryker have reduced taper support (13 mm versus 15 , and $17 \mathrm{~mm}$ ) with increased bending and torsional moments (Figure 16c), which produces much higher stresses at the modular junction and
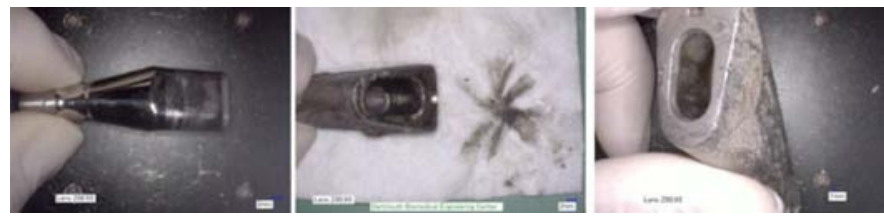

Figure 15. Retrieval of taper corrosion with dissimilar metals-cobalt-chrome alloy modular neck on titanium Stryker stem. (Courtesy of Dartmouth Biomedical Engineering Center.) 


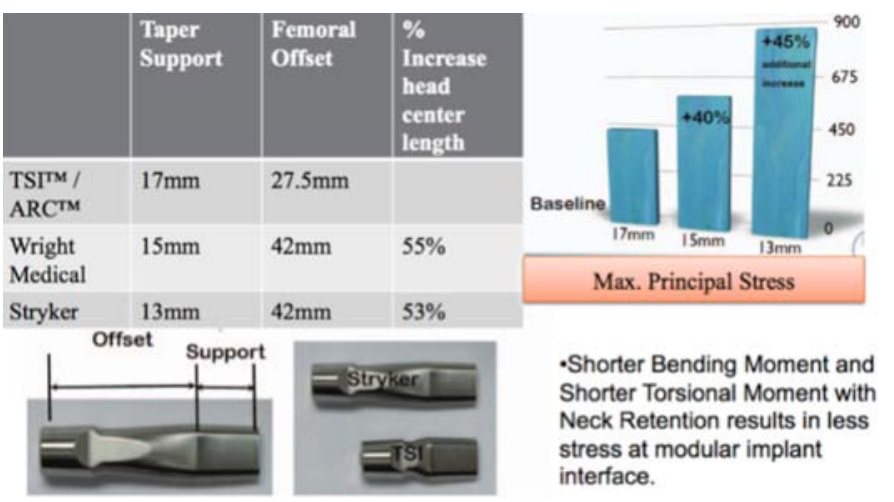

Figure 16a. Showing Modular Necks taper support engagement and percent increase in stress for engagement support.
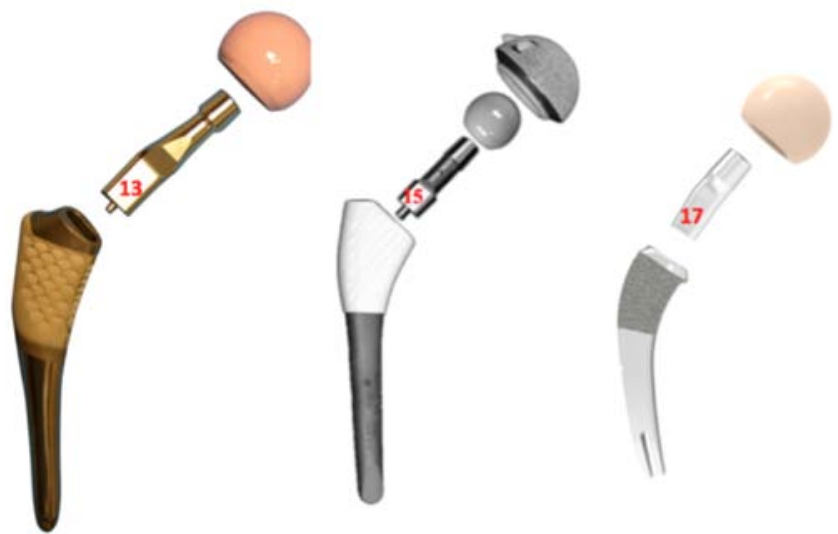

Figure 16b. Modular Neck/Stem Designs showing neck/stem taper engagement length (Stryker ABG II Modular-13mm, Wright-15 mm, ARC-17mm) (Courtesy of JISRF)

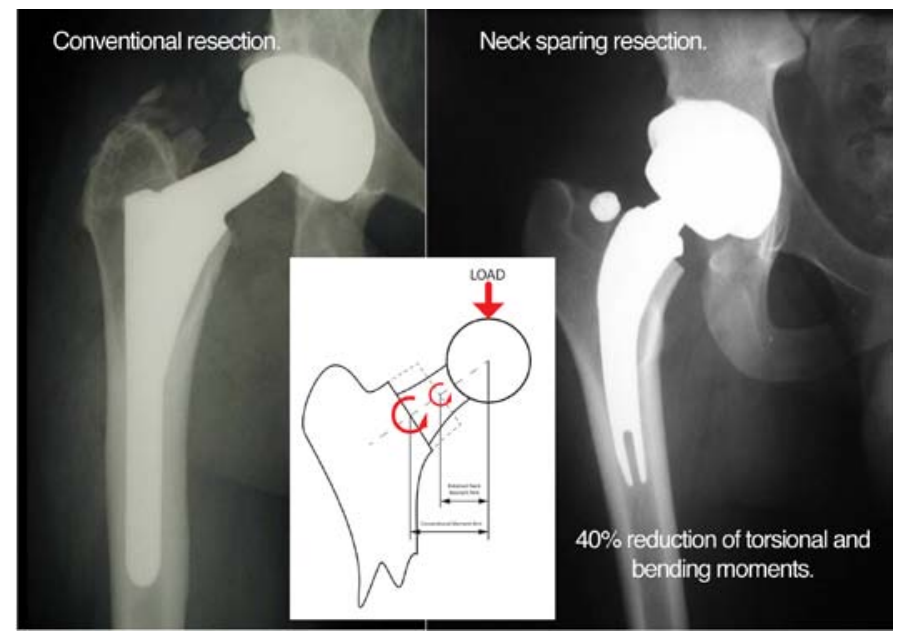

Figure 16c. Two Postoperative X-rays showing different level neck resections and offsets resulting in less bending and tosional moments in the neck-sparing implant. (Courtesy of JISRF)

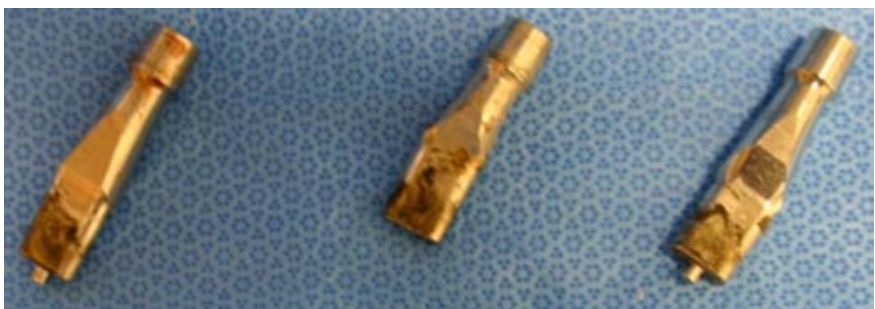

Figure 16d. Explanted Stryker ABG II Modular Necks Showing Fretting and Corrosion (Courtesy of WL. Walter)

potentially leads to a more rapid fretting corrosion rate as compared with neck preserving style stems (Figure 16d). $[7,8]$ Figure 17 shows results of presentation by Brazil and McTighe on FEA modeling comparing level of neck resection (neck sparing stem versus conventional); as compared with a conventional neck resection, the neck sparing resection results in a $35 \%$ reduction in principal tensile stress. [46]

Recent marketing trends have also contributed to problems at the modular junction. The use of large femoral heads (greater than $36 \mathrm{~mm}$ ) M-o-M bearings, increased femoral offset, increased leg length, and reduced precautions on patient-related physical activity may result in higher stresses at the modular junction. [7,8] These actions

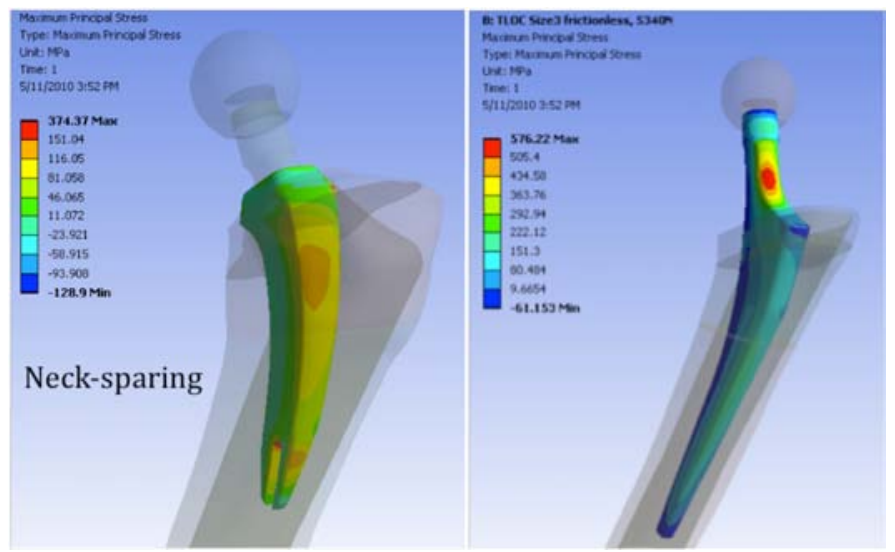

Figure 17. FEA Modeling showing 35\% less tensile stress in a neck-sparing resection compared to a conventional neck resection. (Courtesy of D. Brazil)

increase torque moment at the modular implant interface. On average, a 1-mm true lateral increase to the ball center offset will increase torque values by $8 \%$. A 1 -mm increase in vertical height (leg length) will increase torque by $6 \%$ (Figure 18).

Reduced taper engagement area, along with increased patient body weight and increased physical activity levels, places significant torsional loads on the implant. Torque $>$ Per $1 \mathrm{~mm}$ increase in true lateral ball-center
offset increases torque by $8 \%$

$>$ Per $1 \mathrm{~mm}$ increase of ball's neck-length increases torque by $6 \%$

\begin{tabular}{|l|l|l|}
\hline Offiset & $\begin{array}{l}\text { Neck- } \\
\text { Length }\end{array}$ & Nm \\
\hline $35 \mathrm{~mm}$ & 49.50 & 84 \\
\hline $40 \mathrm{~mm}$ & 56.58 & 96 \\
\hline $45 \mathrm{~mm}$ & 63.65 & 108 \\
\hline $50 \mathrm{~mm}$ & 70.72 & 120 \\
$55 \mathrm{~mm}$ & 77.79 & 132 \\
\hline
\end{tabular}

Figure 18. Chart Showing Torsional Loads per offset and neck-length (Courtesy of Ian Clarke) 
is a force applied over a distance (lever arm) that causes rotation about a fulcrum (axis of rotation) (Torque=Force (Fm) x Moment Arm). The greater the torque a muscle can produce, the greater the movement it will produce on the body's levers. [45] Example of patient at risk would be an active male weighing $250 \mathrm{lbs}$ with a $50 \mathrm{~mm}$ femoral offset, a combination that would generate in excess of $70 \mathrm{ft}-1 \mathrm{bs}$ of torque. Design limit for most tapers is approximately $60 \mathrm{ft}-$ lbs. We know by previous reports that the hip sees torque values over $95 \mathrm{ft}-\mathrm{lbs}$, as demonstrated in some mechanical failures of first generation modular hip stems [13] (Figure 19).

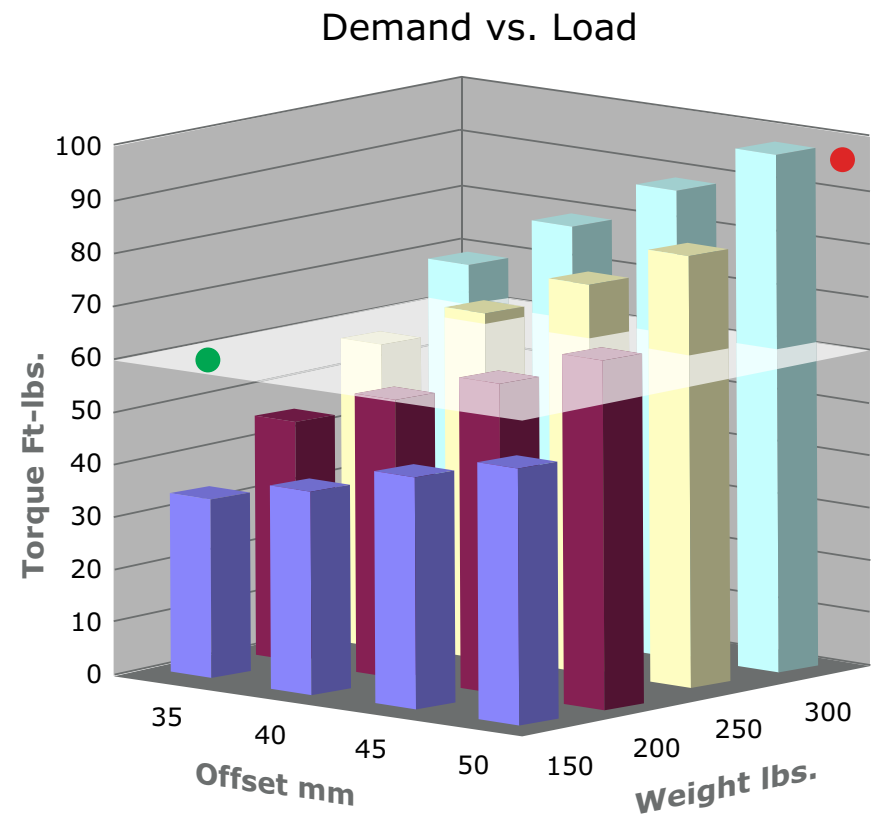

We know the hip generates loads above $90 \mathrm{ft}$-lbs.

Design limit $60 \mathrm{ft}$-lbs.

Figure 19. Chart Showing Torque Loads Generated by Femoral Offset and Body Weight.

One such torsional failure mode was presented as a poster exhibit at the 2006 ISTA Annual Meeting reporting on a proximal modular neck design that featured a "Dual Press $^{\mathrm{TM}}$ " modular junction. The Dual Press modular junction employs two areas of cylindrical press-fit (Figure 20). This allows the proximal portion of the shoulder to fully seat, providing medial support, which increases strength and allows higher lateral offsets. The rotation of the proximal body is restricted by a locating pin. The pin strength was established at 95ft-lbs, well above historical published reports on torsion. These modular junction failures were not a fatigue failure mode, and no surgical errors or fabrication defects were found. The culprit appeared to be patient activity resulting in a mechanical overload in a static shear mode failure (perfect storm). The solution was rather
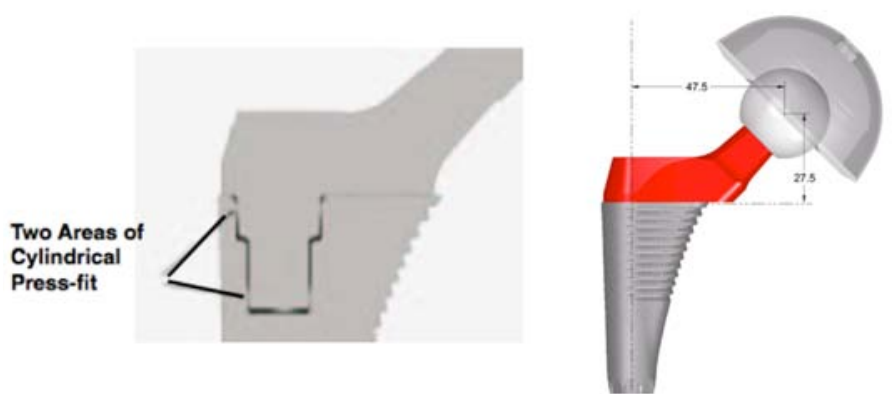

Figure 20. Dual-Press Modular Junction (Omni, East Taunton, MA) Illustration Showing two areas of press fit allowing proximal shoulder to sit flush with stem body.

simple: replace the old pin diameter from .125 " to .188 " and change the old plug to a new feature of a bolt that engages the stem. This revision resulted in $225 \%$ increase in torsional strength. It serves as an example that changes and improvements are possible once there is a full understanding of the problem. There have been no reported mechanical failures of its modular junction since 2004 with the improved design (Figure 21a, 21b, 21c) .

Since 2004, there have been more than 7,000 Omni
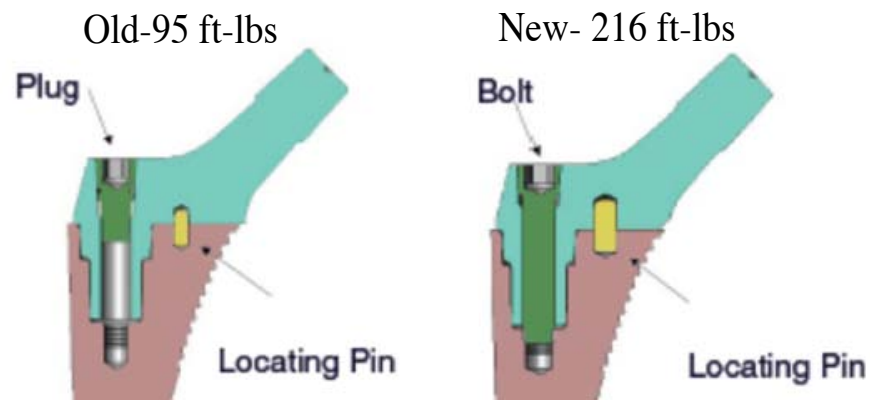

Figure 21a. Illustration showing old Dual-Press design to new improved design increasing torsional resistance from $95 \mathrm{ft}$-lbs to $216 \mathrm{ft}-\mathrm{lbs}$.

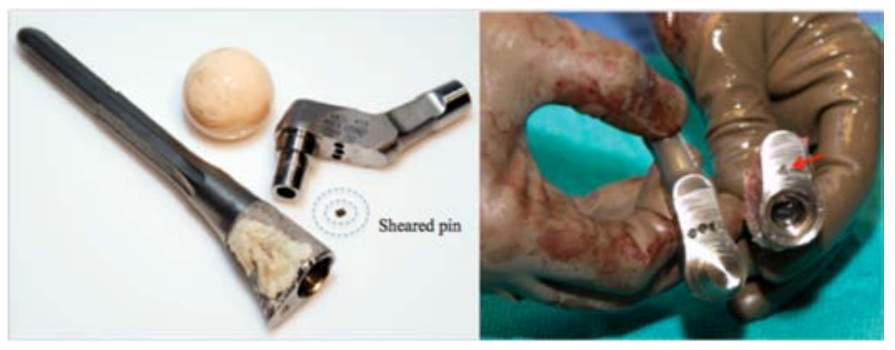

Figure 21b. Explanted Apex Modular Stem (Dual Press Modular Junction, Omni, East Taunton, MA) showing sheared de-rotation pin and fretting abrasion wear. No signs of corrosion. (Courtesy of Keggi)

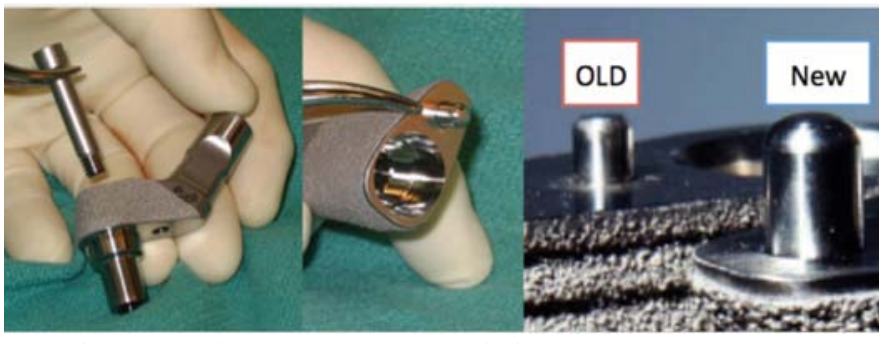

Figure 21c. Picture showing old pin diameter of .125" to new diameter of .188 "increase in strength $(+225 \%)$. (Courtesy of K. Keggi) 
MOD II and more than 3,000 Omni K2 Dual Press improved junctions implanted. Seventeen revisions involving the OMNI MOD (.23\%) and four involving the OMNI K2 Stems $(0.12 \%)$ have been reported to OMNI. Of these, two involved increased metal ion levels (as determined by the patient's physician), and in both cases the OMNI MOD Stem was used with another manufacturer's M-o-M femoral head and acetabular cup bearing combination. The revisions involved removing the competitor's head and cup and replacing the OMNI MOD Modular Neck, leaving the stem in place. There have been no other reports of metal ion concerns, corrosion, or fretting with the OMNI MOD and OMNI K2 Modular Stems. [47]

Another example of modular neck failure was the original OTI ${ }^{\mathrm{TM}} \mathrm{Co}-\mathrm{Cr}-\mathrm{Mo}$ modular neck that interfaced with a Co-Cr-Mo stem. The failure mode for this device was basic fatigue failure caused by an under-designed modular junction. Improvements made to this novel neck design, which increased surface contact by $40 \%$, included specific size increases of the taper trunnion that improved mechanical strength from 520-700 lbs to greater than 1,200 lbs (Figure 22a and 22b). To our knowledge, there has been no reported failures with the improved modular junction design. [48,49]

Our own research using a short-curved neck sparing modular neck that mates with a Co-Cr-Mo neck with Tialloy stem is undergoing extensive fretting and corrosion testing of the additional surface coating of selected regions of the Co-Cr-Mo modular neck with titanium nitride (TiN).

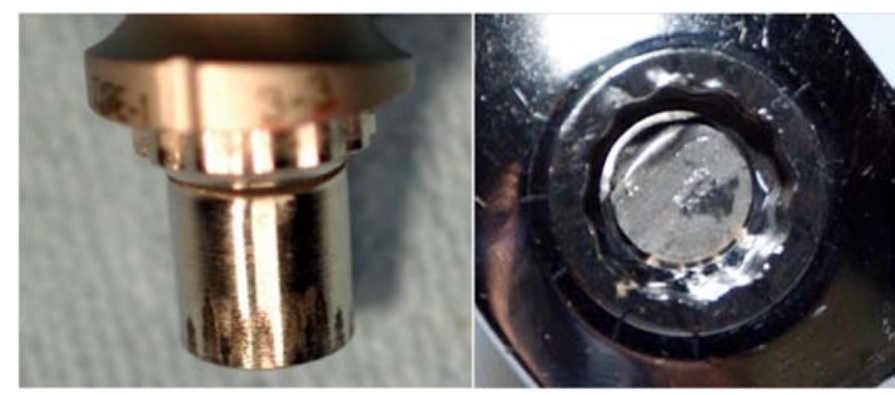

Figure 22a. Pictures showing a fatigue failures in explanted OTI Co-Cr-Mo modular neck and close up of broken neck within the stem cone body. Stem, neck and head are Co-Cr-Mo. (Courtesy of JISRF)

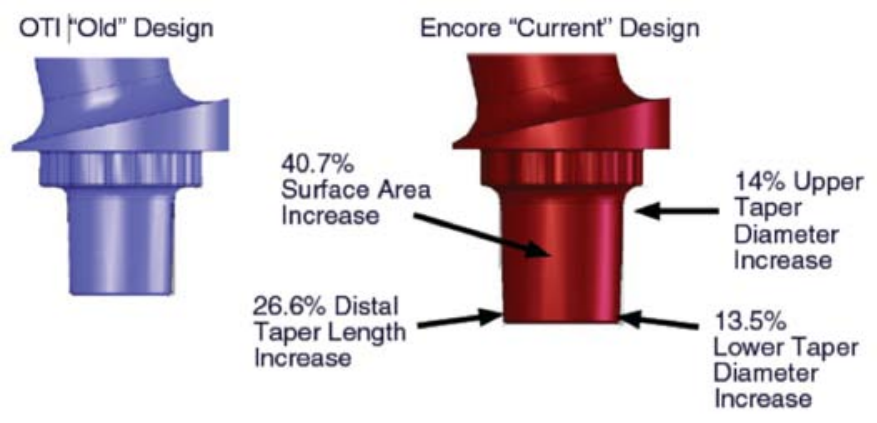

Figure 22b. Illustration showing modular taper improvements from the original OTT ${ }^{T M}$ design to the Encore improvement design. (Courtesy of JISRF)
This material process reduces the potential galvanic reaction between the materials and consequently reduces the probability of corrosion between mating surfaces. This fundamental design concept can be further applied to the internal surfaces of the femoral head that interfaces with a Ti-alloy stem taper. Our initial results have been presented at various $\mathrm{CME}$ meetings with very favorable results in reduction of fretting abrasion wear between the TiN distal coated necks versus non coated necks. $[7,8,36,37]$ TiN fully coated necks saw the

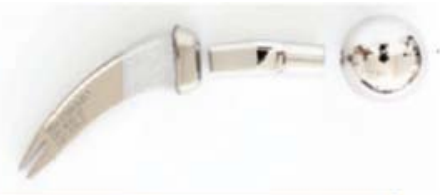

A. Uncoated Neck

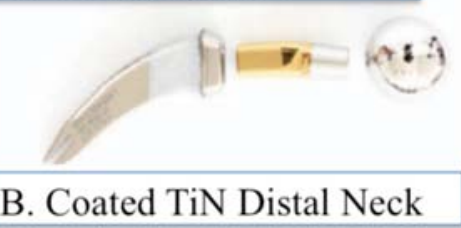

B. Coated TiN Distal Neck

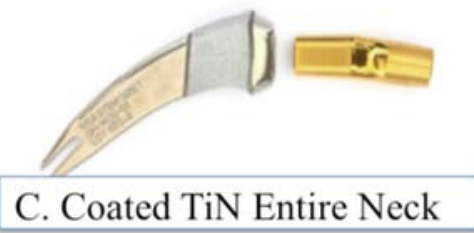

Figure 23. Showing test samples (ISO72066 Setup 5340 N-10 Million Cycles Measured Abrasive Wear) comparing TiN coated modular Co-Cr-Mo necks interfacing with Ti-alloy stems.

- The TiN distal coated necks (B) showed significantly less fretting wear when tested under the same load conditions as group A.

- The fully coated necks $(C)$ showed the same results as group $(B)$ for the distal neck and no difference interfacing with $\mathrm{Co}-\mathrm{Cr}$-Mo heads.

same results for the distal coated necks but saw no difference in the proximal portion interfacing with a Co-Cr-Mo femoral head (Figure 23).

\section{Challenges with the Stem/Sleeve Modular Junction}

The success of the S-Rom ${ }^{\circledR}$ modular stem system stimulated most companies to rush into the market with a modular style hip. $[9,38,39]$ The S-Rom stem, an evolution of the original Sivash stem, experienced a number of design changes before becoming the novel design that still survives today. Most think the modular features were the single most important factors to its success. In reality, the clinical success can be contributed to its basic geometric design that provided for immediate implant stability with the potential for long-term fixation with a reproducible surgical technique. The modular features are secondary to its basic geometric structure.

Fracture of the S-Rom stem is rare; however, it does happen, and fractures have been reported at different sites in the femoral stem body. Pearce et al reported two stem fractures at the mid-stem junction at the top of the slotted portion of the stem. $[40,41,42]$ One of our authors had a fractured stem (4 years postoperatively) within the sleeve/ 


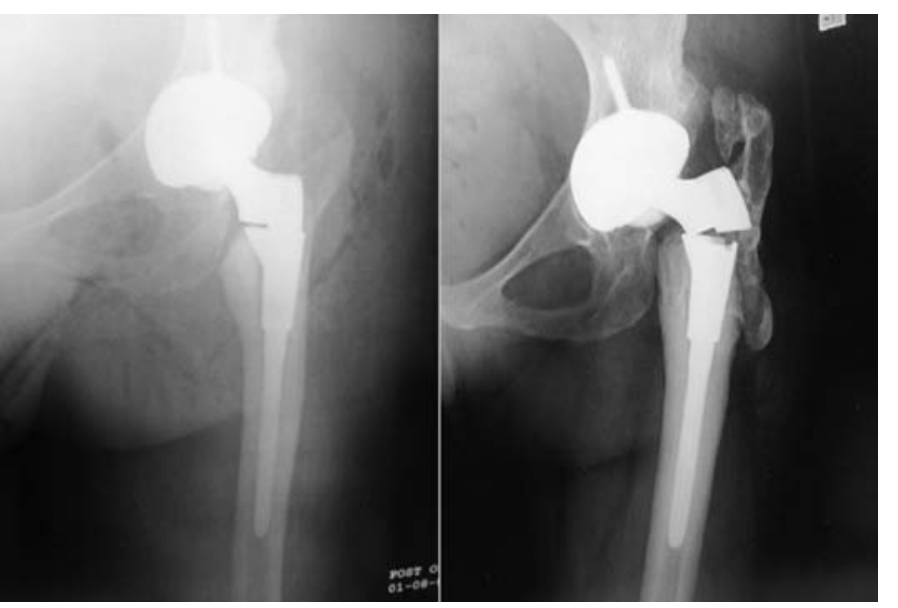

Figure 24. Two postoperative X-Rays showing a S-Rom stem used for a DDH patient that sustained a fracture of the proximal stem within the modular sleeve area. (Courtesy of J. Keggi)

stem junction in a DDH patient that requiring the smallest S-Rom stem $(9 \mathrm{~mm})$ (Figure 24). We are also seeing some signs of corrosion at the stem/sleeve junction. Urban et al reported at the 53rd Annual Meeting of the Orthopaedic Research Society on 30 retrieved stems of three different style modular titanium stems (16 S-Rom, 11 ZMR, 3 Mallory-Head); all of the devices had a Co-Cr-Mo head. Corrosion and fretting damage was observed at 20 of the 30 devices. A wide range in the degree of damage, ranging from minimal to severe, was observed in each of the 3 designs examined. Overall, the damage was minimal in 10 stems, mild in 11 , moderate in 6 , and severe in 3 . In two stems, severe corrosion may have contributed to fatigue fracture. [43]

One area of observation is the process of grit-blasting titanium stem surfaces, which leaves a matte or satin finish (Figure 25). Grit surfaces were introduced in the early 1980 s for cemented stems, with the belief that the slightly rough surface finish (RA: $.7 \mu \mathrm{m}$ ) would provide improved bonding of the bone cement interface. Results were just the opposite, with higher aseptic loosening occurring in the grit-blasted stems than in polished stems. $[44,45]$ In retrieving roughened Spectron $\mathrm{EF}$

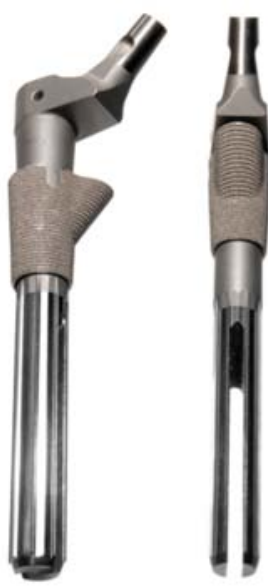

Figure 25. S-Rom® Stem with proximal modular porous sleeve. (Courtesy of JISRF) stems (Smith and Nephew, Memphis, TN, USA), Gross et al reported the presence of macroscopic metallosis in all hips. The microscopic examination of the femoral pseudomembrane consistently revealed an inflammatory reaction characterized by the presence of multinucleated giant cells and metallic, cement, and poly- ethylene deposits. [44] In 1992, Buly et al reported on 71 cases of titanium wear debris in failed cemented THA. Femoral bone loss in aseptically loose, primary THA was graded as severe in $51 \%$, moderate in $24 \%$, and mild in $20 \%$. Femoral endosteolysis was present in $94 \%$, while acetabular osteolysis was seen in 6\%. Histological evaluation of tissues from failed primary arthroplasties revealed polymethyl methacrylate debris in $75 \%$ of cases, polyethylene debris in $80 \%$, metal debris in $75 \%$, and chronic inflammatory cells in all cases. [46] One can conclude from past reports and personal observations that rougher surfaces that interface with another rough surface (bone, cement, metal) under micro or macro movement will suffer fretting abrasion wear.

Many manufactures use the bead blasted or matte finish on titanium stems as a cosmetic process to cover or reduce machine marks from the fabrication process. Figure

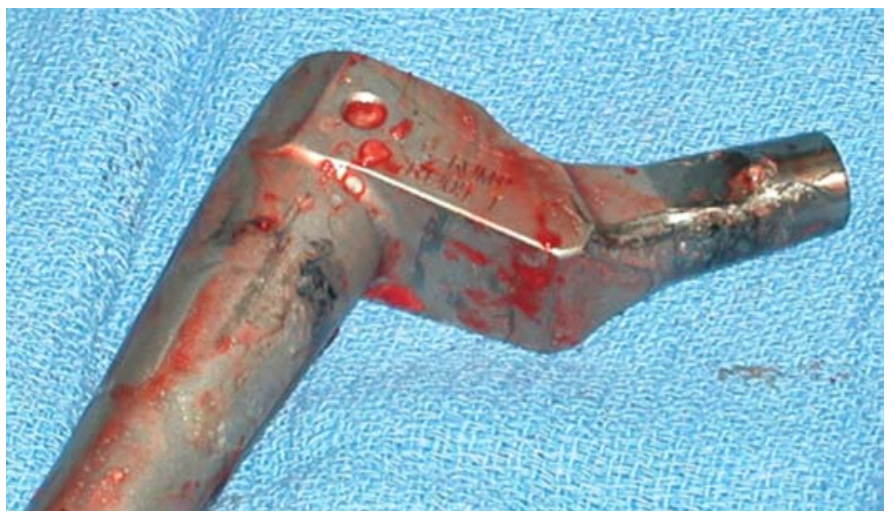

Figure 26. Explanted S-Rom Stem showing surfaces scaring (metal transfer) on the proximal stem under the modular sleeve and under the shoulder of the stem. This demonstrates micro-movement between the modular junction. (Courtesy of JISRF)

26 shows a retrieved S-Rom stem with surface scarring, demonstrating metallic transfer of particles at the modular stem/ sleeve junction. The abrasive wear at titanium surfaces can affect the metal protective oxide (passivation) layer on the surface of the implants and corrosion can be introduced when this (protective) passivation layer is damaged.

The modular taper connection of the stem/sleeve, which allowed intraoperative customization, did not and does not currently provide sufficient rotational stability to withstand the torsional loads brought about by normal cyclic movement.

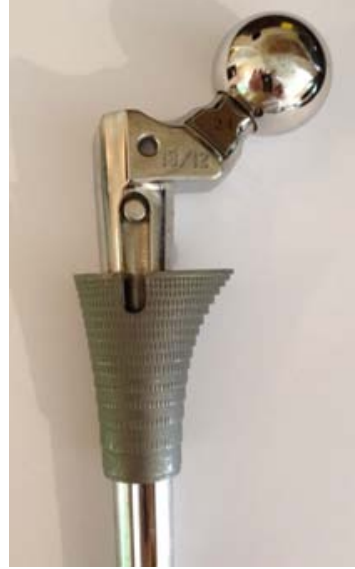

Figure 27a. 1984 Polished S-Rom $125^{\circ}$ Stem with Proximal Modular Sleeve that engaged a derotational locking pin in the stem. (Stem Ti-alloy, Ti-alloy Modular Sleeve \& Co-Cr-Mo Modular Head. (JMPC, Stanford, CT) (Courtesy of JISRF) 
The original S-Rom $125^{\circ}$ stem (1984) had a locking pin through the stem that engaged with the proximal sleeve, reducing the risk of stem slippage within the sleeve (Figure $27 \mathrm{a}$ and $27 \mathrm{~b}$ ). One additional problem with the 1984 design was a groove that ran down the anterior/posterior

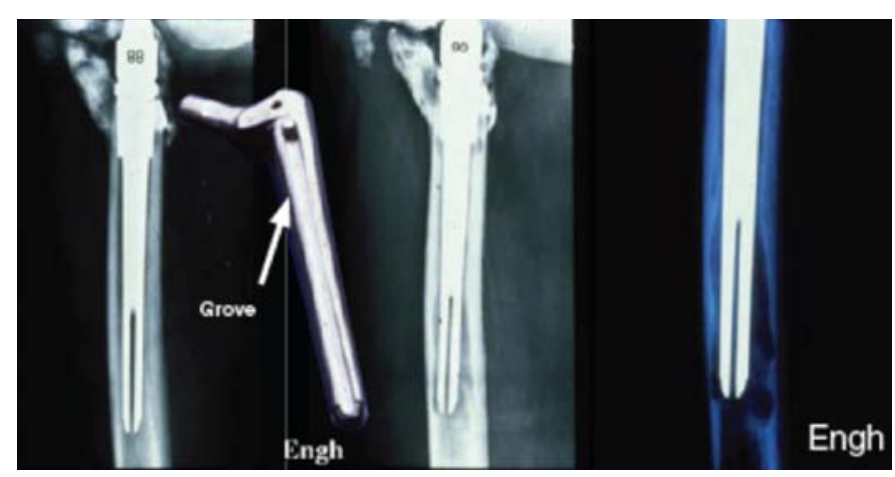

Figure 27b. X-rays of a S-Rom $125^{\circ}$ Stem (1984) showing progressive distal osteolysis over a three-year period. (Courtesy C. Engh \& JISRF)

portion of the entire length of the stem. In a poster exhibit at the 2006 ISTA annual meeting, one of our coauthors presented an example of progressive distal osteolysis, in which particulate debris migrated down the grooved stem. This helped make the decision of adding distal flutes, eliminating the groove, and eliminating the locking pin. Another concern with regard to the concept of stem/sleeve modularity is the risk of increasing the length beyond the taper engagement contact zone. During the 1980s, one of our coauthors was part of the S-Rom design team; their study group (Cameron, Mallory, Bierbaum, Bobyn, Moreland, Pugh, Greenwald, Noiles and McTighe) reviewed the design and ruled it out because of increased risk of fretting abrasion wear between distal sleeve and stem (Figure 28). Bending moments can be increased, especially with thinner stem diameters.

EMPERION sleeve options
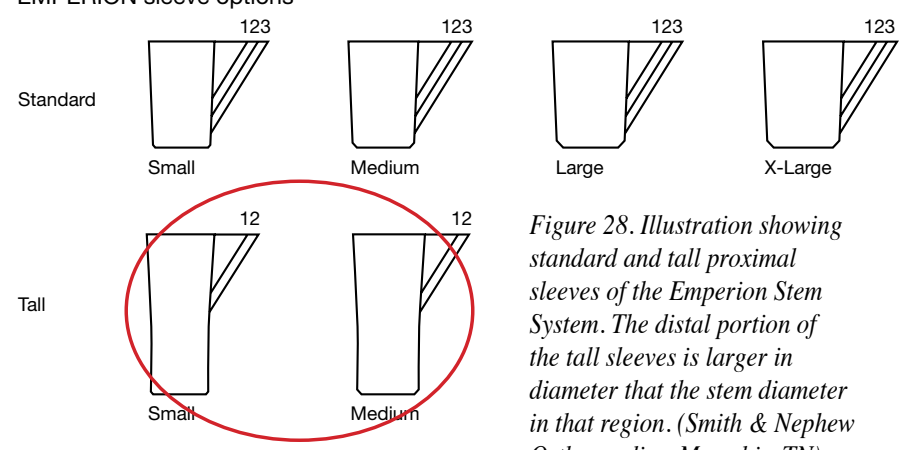

Figure 28. Illustration showing standard and tall proximal sleeves of the Emperion Stem System. The distal portion of the tall sleeves is larger in diameter that the stem diameter in that region. (Smith \& Nephew Orthopaedics, Memphis, TN) shelf style taper allows for more standard revision options as compared with using a taper neck sleeve adapter. Neck taper adapters may have limitations in design by having skirts that may interfere with range of motion or cause impingement, resulting in generation of particulate debris and or dislocation (Figure 29).

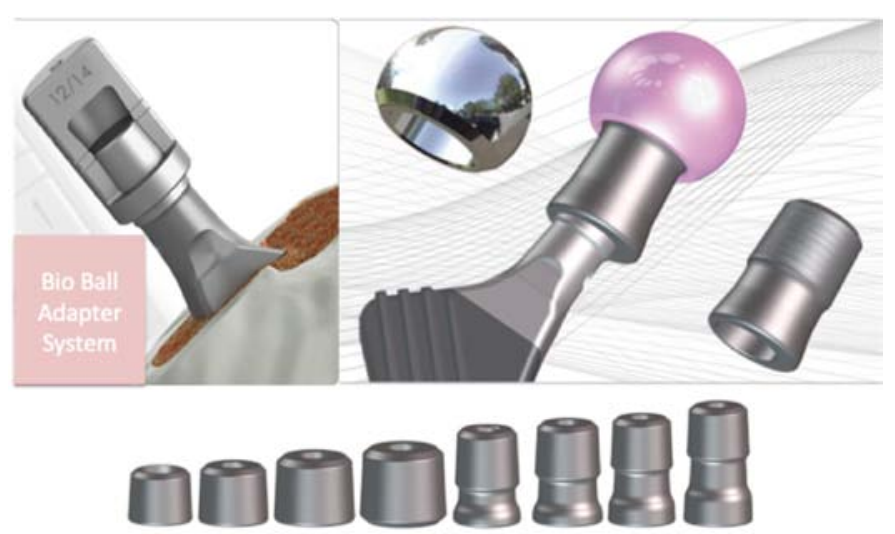

Figure 29. Femoral neck adapters that can convert a smaller taper (11/13 to 12/14) to a larger for revision surgery.

This design concept allows for adjustment of head center vertical height and head center lateral offset. In addition, this feature allows for mixed materials to be selected for the articulation of the bearing surface. The femoral head is commonly fabricated from a Co-Cr-Mo alloy or an alumina-based ceramic. Our research on TiN of Co-Cr-Mo modular necks interfacing with Ti-alloys stems might be carried over to just coating the inside of a Co-Cr-Mo head to reduce potential galvanic reaction of dissimilar materials and reduction of micro-fretting abrasion wear at the head/ neck interface. Another improvement already in practice is going back to the concept of a more hemispherical head. This improves the surface contact area for head/neck trunnions that can reduce

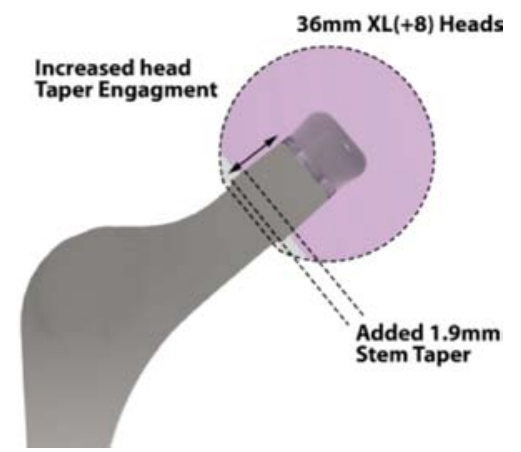

Figure 30. Illustration Showing Increased Surface Contact between Femoral Head and Stem Trunnion by Increasing Contact Length of Taper. stress and micro-motion at the interface (Figure 30).

\section{Challenges with Head/Neck Modularity}

As taper lengths and taper ratios have changed over the years, standardizing on a 12/14 Euro Ceramtec off-the-

\section{Summary and Conclusion}

The use of metallic modular junctions in hip replacement has increased since the early 1980s, and some might say they are overused. We are seeing an increased num- 
ber of complications associated with modularity, including dissociation, corrosion, wear, fretting, and fatigue failure. When modular implants were first introduced, the biggest challenge was the frequent fracture of ceramic heads. Today-more than 40 years after the introduction of modular ceramic heads - fracture is rare, and ceramic modular heads have demonstrated low wear rates, outstanding biocompatibility, diamond-like hardness, and high resistance to third-body wear.

Metallic heads made of titanium alloy proved to be unsatisfactory, increasing wear at the articulation. Metallic heads made from Co-Cr-Mo alloy are strong, and they pose no potential of failure by fracture or fatigue. However, fretting, corrosion, and micro-motion are still major concerns. Modular implants with titanium alloy stems and Co-Cr alloy heads were introduced in order to take advantage of the lower stiffness of Ti alloy for better load transfer to bone while making use of higher wear resistance of Co-Cr alloy heads. The use of these modular implants soon gave rise to corrosion at the modular mating surfaces, which was first thought to be galvanic in nature because the dissimilar materials were involved. Further investigations on Morse taper connections of modular hip prostheses brought about different conclusions on the nature of modular interface failures. Stress, strain, and micromotion at the modular interface can induce fretting abrasion wear, resulting in the generation of particulate debris, increased release of metal ions, corrosion, and adverse tissue (local and systemic) reaction.

Analysis shows that you must carefully consider patient weight and activity level when implanting a hip stem of any design. A 350-pound active male with a $50 \mathrm{~mm}$ offset and a $11 \mathrm{~mm}$ distal stem exceeds the fundamental fatigue strength of titanium alloy, regardless of proximal stem design or modularity.

Taper issues are the same regardless of where the taper is located (head/neck, neck/stem, mid-stem, or stem/ sleeve). Reducing risk associated with tapers can be ameliorated through many strategies; design characteristics such as a large surface contact (length and diameter), stiffer material (less deflection), and tight manufacturing tolerances can reduce stress, strain and micro-motion at the modular junction. This reduces fluid ingress and the extent of fretting that could trigger corrosion by depassivating the protective metallic oxide layers and setting up a crevice corrosion cell. Careful intraoperative techniques for assembly are critical. Both male and female trunnions must be clean and dry before assembly, and proper force must be used to engage the modular junction.

Generation of particulate debris can often be reduced through the careful selection of implant material and fab- rication. This problem is worse with Ti-based implants because of lower hardness and abrasion resistance. Also, some implant preparation techniques such as bead blasting tend to leave residual contaminants (silica or alumina) that can be dislodged by abrasion at the modular interface. Bead-blasted taper surfaces can produce surface scarring that is material transfer brought on by micro-motion. Taper surfaces should be clean and smooth, then micro-etched with chemical-milling techniques in the fabrication process. Debris can migrate throughout the joint space, accessing any and all implant interfaces. Select designs and material that provide immediate secure fixation that minimize micro-motion, stress, and strain.

The following are some examples of actions to reduce the generation of particulate debris:

- Head/neck tapers: Use 12/14 (Larger and stiffer surface contact area) taper over smaller tapers such as 11/13 or $9 / 10$ when possible.

- Head/neck tapers: Increasing taper length will reduce micro-motion.

- Stem tapers: Many tapers do not have adequate intrinsic stability for high activity, so limit modular junctions or pick designs that have back-up features to support taper junctions (e.g., fluted stems).

- Reduce fatigue failure of modular necks by material choice. Co-Cr-Mo is stronger than Ti-alloy.

- Reduce potential galvanic corrosion of dissimilar metals by TiN coating Co-Cr-Mo necks used with titanium stems.

- Reduce micro-motion, stress, and strain in modular necks by increasing taper engagement.

- Reduce micro-motion, torsional moment, and bending moment on stems (modular necks) by selecting neck sparing stem designs that retain the femoral neck.

- Caution should be used in selection of modular junctions in highly active males that exceeds 250 pounds.

Modular designs have made significant contributions to reconstruction of the diseased and damaged hip-from improving fit and fill of the implants to restoring joint mechanics. While problems have been reported with the use of modularity, the collaborative orthopaedic community (industry, surgeons, and scientists) has been successful in identifying and providing solutions to improve overall designs and outcomes. Modularity can be designed and fabricated to provide safe, reliable, and reproducible clinical results.

As an example of industry stepping up identifying problems and initiating actions from 2002 to 2013, the six largest implant companies have voluntary recalled 578 hip implants as compared with the FDA using its recall authority three times in 20 years. 
It is important to remember all devices are subject to failure. It is also necessary to recognize design and material limits and not to over-indicate in high-risk patients. A number of modular junctions have come and gone from clinical use. Nevertheless, the endeavor to improve clinical outcomes should be continued. Modularity can be designed and fabricated to provide safe, reliable, and reproducible clinical results.

Because there are no laboratory tests allowing accurate prediction of the service life and performance of implant parts, clinical experience with a large number of cases over a period of several years is the only reliable indicator. However, clinical evaluations should only begin after conducting aggressive basic science material and mechanical testing to anticipate potential failure modes. Individual patient physical activities should be considered when deciding on stem modularity features. Since there are no standards established for modular junctions the overall performance of modular junctions are not equal. Careful review of basic engineering principles is necessary and recognizing design limits will reduce the indication of overuse.

To advance scientific knowledge in the long run often requires some short-term setbacks.

\section{Disclosure Statement:}

One or more of our authors have disclosed information that may present potential for conflict of interest with this work. For full disclosures refer to last page of this journal.

\section{Acknowledgement}

The authors thank Chris Burgess, I. Clarke, A. John, J. Keggi, K. Keggi, Evert Smith, and Dartmouth Biomedical Engineering Center for pictures and illustrations.

\section{References}

1. Cameron H, Trick L, Shepherd B, et al. An international multi-center study on thigh pain in total hip replacements. American Academy of Orthopaedic Surgeons 1991 Scientific Exhibit, New Orleans, Louisiana. DOI: http://dx.doi.org/10.13140/RG.2.1.2093.2641

2. Mattingly D, McCarthy J, et al. Revising the deficient proximal femur. American Academy of Orthopaedic Surgeons 1991 Scientific Exhibit, Anaheim, CA. DOI:http://dx.doi org/10.13140/2.1.3611.7289

3. Keppler L, Cameron H, McTighe T. The Role of Modularity in Primary THA: Is There One? American Academy of Orthopaedic Surgeons 2006 Scientific Exhibit, Chicago, IL. DOI: http://dx.doi. org/10.13140/RG.2.1.2132.5923

4. Tkach T, Low W, Cipolletti G, McTighe T. Target Restoration of Hip Mechanics in THA. American Academy of Orthopaedic Surgeons 2006 Scientific Exhibit, Chicago, IL. DOI: http://dx.doi org/10.13140/RG.2.1.1084.0167.

5. Gilbert JL, Buckley CA, Jacobs JJ. In vivo corrosion of modular hip prosthesis components in mixed and similar metal combinations. The effect of crevice, stress, motion, and alloy coupling. J Biomed Mater Res 1993;27:1533-1544.

6. Berry DJ. Utility of modular implants in primary total hip arthroplasty. The Journal of Arthroplasty 2014;29:657-658

7. McTighe T, Brazil D, Keggi J, Keppler L, et al. Optimizing modular tapers for total hip arthroplasty. http://www.jisrf.org/pdfs/Optimizing-Modular-Tapers-for-Total-Hip-Arthroplasty-ICJR-July2014.pdf. Conference Paper July 2014: International Congress for Joint Reconstruction, Pacific Hilton Waikoloa Village Resort.

8. McTighe T, Brazil D, Bruce W. Metallic Alloys in Total Hip Arthroplasty. In: Cashman J, Goyal N, Parvizi J, eds. The Hip: Preservation, Replacement and Revision. Baltimore, MD: Data Trace Publishing Company; 2015:14-1-14-12.

9. McTighe T. Cementless Modular Stems. JISRF Update, April, 2002 http://www.jisrf.org/pdfs/ce mentless-modular-stems.pdf

10. Bobyn JD, Collier JP, et al., Particulate Debirs in Total Hip Arthroplasty: Problems and Solutions. American Academy of Orthopaedic Surgeons 1993 Scientific Exhibit. DOI: http://dx.dol. org/10.13140/RG.2.1.2355.4080
11. Chana R, Esposito C, Campbell PA, et al. Mixing and matching causing taper wear: corrosion associated with pseudotumour formation. J Bone Joint Surg Br 2012;94:281.

12. Cooper HJ. The local effects of metal corrosion in total hip arthroplasty. Orthop Clin N Am 2014;45(1):9

13. Keggi K, Keggi J, Kennon R, et al. Within any important issue, there are always aspects no one wishes to discuss: femoral component failure. Poster Exhibit International Society for Technology in Arthroplasty, October 2006. DOI: http://dx.doi.org/10.13140/RG.2.1.4779.6329

14. Bechtol CO, Ferguson AB Jr, Laing PG. Metals and Engineering in Bone and Joint Surgery. Baltimore: Williams and Wilkins Company, 1959

15. Willert, H.G. and Semlitsch, M.: Reactions of the articular capsule to wear products of artificial joint prostheses. J. Biomed. Meter. Res. 11:157, 1977.

16. 16Kutz SM, Ong K, et al., Projections of primary and revision hip and knee arthroplasty in the United States from 2005 to 2030. JBJS 89(4):780-5 March 2007 DOI: http://dx.doi.org/10.2106 IBJS.F.00222 Source: PubMed

17. McTighe T, Trick L, Koeneman J. Design Considerations for Cementless Total Hip Arthroplasty. Encyclopedic Handbook of Biomaterials and Bioengineering. Part B Applications Vol I. Marcel Dekker, Inc. 1995 DOI: http://dx.doi.org/10.13140/RG.2.1.2919.0240.

18. Kwon YM, Ostlere SJ, McLardy-Smith P et-al. "Asymptomatic" pseudotumors after metal-on-metal hip resurfacing arthroplasty: prevalence and metal ion study. J Arthroplasty. 2011;26 (4):511-8. DOI http://dx.doi.org/10.1016/j.arth.2010.05.030.

19. Clarke M, Lee P, Aron A, Villar R. Levels of metal ions after small- and large- diameter metal-onmetal hip arthroplasty. J Bone Joint Surg [Br] 2003;85-B:913-7, Received 14 January 2003; Accepted 27 May 2003

20. Innman M, Gotterbarm T, et al. Minimum ten-year results of a $28-\mathrm{mm}$ metal-on-metal bearing in cementless total hip arthroplasty in patients fifty years of age and younger. International Orthopaedics May 2014, Volume 38, Issue 5, pp 929-934

21. Migaud H, Berton C, et al. Head Size and Metal-on-Metal Bearings. Total Hip Arthroplasty 2013, pp 125-140, Springer Berlin Heidelberg 10.1007/978-3-642-35653-7 12

22. McDougall A. Malignant tumour at site of bone plating. J Bone Joint Surg Br. 1956;38(3):709-713

23. Jacobs JJ, Gilbert JL, Urban RM. Corrosion of metal orthopaedic Implants. J Bone Joint Surg Am. 1998;80(2):268-282

24. National Joint Registry. 7th Annual Report for England and Wales. 2010. www.njrreports.org.uk: www.njrcentre.org.uk.

25. Morlock M. The taper disaster: How could it happen? Hip Int 2015;May 20(00):000- 000 DOI: http:// dx.doi.org/10.5301/hipint.5000269

26. Langton DJ, Jameson SS, Joyce TJ, Hallab NJ, Natu S, Nargol AV. Early failure of metal-on-metal bearings in hip resurfacing and large-diameter total hip replacement: A consequence of excess wear. $J$ Bone Joint Surg Br. 2010;92(1):38-46.

27. Hernigou P, Queinnec S, Lachaniette C. One hundred and fifty years of history of the Morse taper: from Stephen A. Morse in 1864 to complications related to modularity in hip arthroplasty. International Orthopaedics 2013;37:2081-2088 DOI: http://dx.doi.org/10.1007/s00264- 013-1927-0.

28. Scheuber L, Usbeck S, Petkow F. The Neck Taper in Hip Arthroplasty-What does the surgeon have to consider? CeramTec Publication, CeraNews 1/2014

29. Keggi K, Keggi J, Kennon R, McTighe T. Ceramic on Ceramic Bearings Used with Proximal Modular Stems in THA. Bioceramics in Joint Arthroplasty/Ceramics in Orthopaedics 2004:3-8 DOI: http:// dx.doi.org/10.13140/RG.2.1.3403.9846

30. Langton et al. Accelerating failure rate of the ASR total hip replacement. J Bone Joint Surg [Br] 2011;93-B:1011-16

31. Barrack R, Burke D, et al. Complications Related to Modularity of Total Hip Components. J Bone Join Surg [Br] 1993; 75-B:688-92

32. NASA Corrosion Technology Laboratory. Forms of Corrosion. Available http://corrosion.ksc.nasa. gov/corr forms.htm.

33. Pastides P, Dodd M, Sarraf K, Willis-Owen C. Trunnionosis: A pain in the neck. World J Orthop 2013 Oct 18;4(4):161-166 DOI: http://dx.doi.org/10.5312/wjo.v4.i4.161.

34. Modular Neck Stem Voluntary Recall Information. Available at http://www.aboutstryker.com/modularneckstems/.

35. Pivec R, Meneghini M, Hozack W, et al. Modular Taper Junction Corrosion and failure: How to Approach a Recalled Total Hip Arthroplasty Implant. J Arthroplasty. 2014;29(1):1-6.

36. McTighe T, Brazil D, Keggi J, Keppler L, et al. Short-Stem Designs for Total Hip Arthroplasty: Neck Stabilized Femoral Components. In Callaghan J, Beaule P, Clohisy J, et al. The Adult Hip. 3rd ed. Philadelphia: Wolters Kluwer Health, in press.

37. Brazil D, McTighe T. Taper Issues in Total Hip Arthroplasty. Oral Paper, 2014 International Congress for Joint Reconstruction, CME Meeting, Sydney, Australia. DOI: http://dx.doi. org/10.13140/2.1.1748.2889

38. Keppler L, Cameron HU, McTighe T. The role of modularity in primary THA: Is there one? AAOS 2006 Scientific Exhibit, Chicago, IL http://www.jisrf.org/pdfs/modulartity-primary-tha.pdf. J Arthroplasty 2006; 21(4 Suppl 1):89-92.

39. Design features and early clinical Results with a modular proximally fixed low bending stiffness uncemented total hip replacement. AAOS 1998 Scientific Exhibit, Atlanta, GA. DOI: http://dx.doi. org/10.13140/RG.2.1.4714.7040.

40. Pearce S, Jenabzadeh A, Walter W, et al. Spontaneous fracture of diaphyseal stem of S-ROM femora prosthesis. BMJ Case Reports 2014; DOI:http://dx.doi.org/10.1136/bcr-2013-202813.

41. Waly F, Abduljabber FH, Gascoyne T, et al. Stem-sleeve junction failure of a modular hip system: retrieval analysis. HSS Journal Case Report. DOI: http://dx.doi.org/10.1007/s11420-015-9455-7. Published online July 9, 2015

42. Patel A, Bliss J, Calfee RP, et al. Modular femoral-sleeve junction failure after primary total hip arthroplasty. JArthroplasty, 2009;24(7):1143. E1-5. DOI: http://dx.doi.org/10.1016/j.arth.2008.09.006.

43. Urban RM, Gilbert JL, Jacobs J. Corrosion and corrosion products generated by three designs of cementless hip stems with a ti-alloy/ti-alloy modular-body junction. 53rd Annual Meeting of the Orthopaedic Research Society, Paper No: 0277.

44. Grose A, Gonzalez A, Bullough P, et al. High failure rate of a modern, proximally roughened, cemented stem for total hip arthroplasty. Int Orthop. 2006;30(4):243-247.

45. Collis DK, Mohler CG. Comparison of clinical outcomes in total hip arthroplasty using rough and polished cemented stems with essentially the same geometry. J Bone Joint Surg Am 2002;84-A:586-592.

46. Buly RL, Hou MH, Salvati E, et al. Titanium wear debris in failed cemented total hip arthroplasty. An analysis of 71 cases. J Arthroplasty. 1992;7(3):315-23 